\title{
Preliminary Tests of Particle Image Velocimetry for the Upper Plenum of a Scaled Model of a Very High Temperature Gas Cooled Reactor
}

\author{
Kyle L. McVay ${ }^{1}$, Jae-Hyung Park ${ }^{1}$, Saya Lee ${ }^{2}$, Yassin A. Hassan ${ }^{1,2}$, N.K. Anand ${ }^{1}$ \\ Department of Mechanical Engineering, Texas A\&M University, 3123 TAMU, College Station, Texas, 77843 \\ Department of Nuclear Engineering, Texas A\&M University, 3133 TAMU, College Station, Texas, 77843
}

\begin{abstract}
The Very High Temperature Reactor (VHTR) is a Generation IV nuclear reactor that is currently under design. During the design process multiple studies have been performed to develop safety codes for the reactor. Two major accidents of interest are the Pressurized Conduction Cooldown (PCC), and the Depressurized Conduction Cooldown (DCC) scenario. Both involve loss of forced coolant to the core, except the latter involves a pressure loss in the main coolant loop. During normal operation a circulator pumps the coolant into the upper plenum and down through the core, but following a loss of forced coolant the natural convection causes the flow to reverse to go through the core into the upper plenum. Computer codes may be developed to simulate the phenomenon that occurs in a PCC or DCC scenario, but benchmark data is needed to validate the simulations; previously there were no experimental test facilities to provide this. This study will cover the design, construction, and preliminary testing of a $1 / 16^{\text {th }}$ scaled model of a VHTR that uses Particle Image Velocimetry (PIV) for flow visualization in the upper plenum. Three tests were run for a partially heated core at statistically steady state, and PIV was used to generate the
\end{abstract}


velocity field of three naturally convective adjacent jets; the turbulent mixing of the jets was observed. After performing a sensitivity analysis the flow rate of a single pipe was extracted from the PIV flow field, and compared with an ultrasonic flowmeter and analytic flow rate. All the values lied within the uncertainty ranges, validating the test results. 


\section{Nomenclature}

$\mathrm{A}_{\text {Coolant }}$ Coolant channel flow area $\left(\mathrm{m}^{2}\right)$

$c_{p} \quad$ Specific heat capacity $(\mathrm{J} / \mathrm{kg} \cdot \mathrm{K})$

$\mathrm{D}_{\text {Hole }}$ Coolant channel diameter (m)

$\mathrm{D}_{\mathrm{CID}}$ Core barrel inner diameter (m)

$D_{m} \quad$ Model hydraulic diameter (m)

$D_{p} \quad$ Prototype hydraulic diameter (m)

$\mathrm{D}_{\mathrm{RV}} \quad$ Reactor vessel inner diameter (m)

d Pipe outlet diameter (m)

g Gravity $\left(\mathrm{m} / \mathrm{s}^{2}\right)$

$\mathrm{L}_{\mathrm{CB}} \quad$ Bottom of the core (m)

$\mathrm{L}_{\mathrm{CT}} \quad$ Top of the core $(\mathrm{m})$

$\mathrm{L}_{\mathrm{RB}} \quad$ Bottom of the lower reflector (m)

$\mathrm{L}_{\mathrm{RT}} \quad$ Top of the upper reflector (m)

$\mathrm{L}_{\mathrm{T}} \quad$ Top of the upper plenum shield (m)

$n \quad$ Maximum number of points in the PIV field $(i, j)$

$N \quad$ Number of frames (number)

$\mathrm{N}_{\text {coolant }}$ Number of coolant channels (number)

$M \quad$ Number of tests (number)

$m \quad$ Test number

$\dot{m} \quad$ Mass flow rate $(\mathrm{kg} / \mathrm{s})$

$\mathrm{P} \quad$ Coolant channel pitch (m)

$\mathrm{P} / \mathrm{D}_{\text {Hole }}$ Pitch-to-Diameter ratio

$Q \quad$ Heat input to core piping (W)

$r \quad$ location vector $(\mathrm{m})$

Re Reynolds number (= $D V / v)$

$\mathrm{Ri}$ Richardson number $\left(=g \alpha \Delta T D / V^{2}\right)$

$\mathrm{S} \quad$ Jet spacing (m)

$T_{i} \quad$ Temperature at core inlet (K)

$T_{o} \quad$ Temperature at core outlet $(\mathrm{K})$ 
$\Delta T \quad$ Temperature gradient $\left(=T_{o}-T_{i}\right)(\mathrm{K})$

$\Delta t \quad$ Time interval of successive images (s)

TI Turbulence intensity $\left(=v_{r m s} / \bar{v}^{N}\right)$

$u \quad \mathrm{X}$-velocity $(\mathrm{m} / \mathrm{s})$

$V_{m} \quad$ Model velocity $(\mathrm{m} / \mathrm{s})$

$V_{p} \quad$ Prototype velocity $(\mathrm{m} / \mathrm{s})$

$v \quad \mathrm{y}$-velocity $(\mathrm{m} / \mathrm{s})$

$v \quad$ velocity vector $(\mathrm{m} / \mathrm{s})$

$v^{\prime} \quad$ Turbulent fluctuations of y-velocity $(\mathrm{m} / \mathrm{s})$

$v_{\text {ave }} \quad$ Average y-velocity between the Tests $(\mathrm{m} / \mathrm{s})$

$v_{r m s}$ Turbulence strength in y direction averaged between the Tests $(\mathrm{m} / \mathrm{s})$

$\bar{v}^{N} \quad$ Average y-velocity for $N$ frames $(\mathrm{m} / \mathrm{s})$

$\Delta X \quad$ Displacement of particle images $(\mathrm{px})$

$\alpha \quad$ Magnification factor $(\mathrm{mm} / \mathrm{px})$

$\beta \quad$ Thermal expansion coefficient $(1 / \mathrm{K})$

$\delta \mathrm{u} \quad$ Experiment uncertainty factor $(\mathrm{mm} / \mathrm{s})$

$\xi_{\dot{m}} \quad$ Mass flow rate uncertainty $(\mathrm{kg} / \mathrm{s})$

$\sigma_{T i} \quad$ Thermocouple error at core inlet (K)

$\sigma_{T o} \quad$ Thermocouple error at core outlet (K)

$\rho \quad$ Density of fluid $\left(\mathrm{kg} / \mathrm{m}^{3}\right)$

$\rho_{0} \quad$ Reservoir fluid density $\left(\mathrm{kg} / \mathrm{m}^{3}\right)$

$\Delta \rho$ Density fluctuation $\left(=\rho-\rho_{0}\right)\left(\mathrm{kg} / \mathrm{m}^{3}\right)$

$\omega \quad$ Vorticity $(=\partial v / \partial x-\partial u / \partial y)(1 / \mathrm{s})$

$v_{m} \quad$ Model kinematic viscosity $\left(\mathrm{m}^{2} / \mathrm{s}\right)$

$v_{p} \quad$ Prototype kinematic viscosity $\left(\mathrm{m}^{2} / \mathrm{s}\right)$

Subscript

m Model

p Prototype 


\section{INTRODUCTION}

The Very High Temperature Reactor (VHTR) has been selected as one of the Next Generation Nuclear Plant (NGNP). It is an evolved Generation IV gas cooled reactor design that allows for a $1,000^{\circ} \mathrm{C}$ coolant outlet temperature [1-4]. The design has high fuel efficiency for electricity generation, and because of the high outlet temperature it is optimal for industrial applications or commercialized hydrogen production $[5,6]$. There are two reactor designs being developed; the pebble bed and prismatic VHTR. Many studies are being performed for both normal operation and accident scenarios for both designs. There are two major accident scenarios of interest; Depressurized Conduction Cooldown (DCC), and Pressurized Conduction Cooldown (PCC) [7, 8]. A DCC event involves the depressurization of the main core coolant loop, generally through a Loss of Coolant Accident (LOCA). This results in an air ingress to the lower plenum where it slowly diffuses into the core and oxidizes with the fuel accelerating the heating of the core and releasing fission products [9]. As there is no heat sink for the core the primary heat removal is through radiation, and the core may reach the failure temperature of $1600{ }^{\circ} \mathrm{C}$. In a PCC scenario there is loss of forced coolant but the main loop stays pressurized, this may be a result of a loss of power. During normal operation the helium is circulated into the upper plenum and down through the core with a blower. Because the loop stays pressurized in a PCC scenario the helium coolant has a high density differential resulting in large buoyancy forces. Over time these forces will overcome the initial inertial forces, reversing the circulation of the coolant to go up through the core into the upper plenum, and down between the reflector and the core. This natural circulation removes sufficient heat from the core so the core will not reach the failing 
temperature of the fuel, but may cause thermal stresses on the internal support structures in the upper plenum.

There are several nuclear system codes currently being developed as computational tools to conduct performance and safety analyses of the VHTR. Experimental models are needed for the validation of these codes. Idaho National Laboratories (INL) has collaborated with Korean and American universities to develop codes as well as experimental models to validate them [8, 10]. Primarily normal operation and air ingress following a DCC scenario were evaluated. To model this, a multi-dimensional gas mixture analysis code was created to predict chemical reaction and thermo-fluid behaviors for an air ingress following a DCC scenario for both pebble bed and prismatic core designs. The Codes were validated with the water pool Reactor Cavity Cooling System (RCCS) test facility, and an inverse U-tube experiment that modeled the temperature and chemical reaction behavior of a gas mixture. Additionally Oregon State University has constructed a high temperature test facility that can model a VHTR during a DCC accident scenario which can provide benchmark data for existing safety analysis codes [9].

Currently there have been many studies and experimental models evaluating the core and lower plenum for normal operation $[4,11,12]$ and DCC accident scenario [7, 9]. There has been CFD analysis for the upper plenum following a PCC Scenario [13]. As there are no experimental models to produce benchmark data for validation, a scaled experimental model of a VHTR is necessary to provide benchmark data in the upper plenum following a DCC or PCC accident scenario. The $1 / 16^{\text {th }}$ scaled test facility constructed in this study can fulfill this deficiency of data. The test facility is a closed loop that uses heated pipes to induce natural circulation through the system without the use of pumps, this may be used to model a DCC event. A pump may be added along with a heat exchanger to simulate a PCC event. Particle Image Velocimetry (PIV) is 
used to obtain the velocity field in the upper plenum. In order to produce benchmark data, the PIV system must first be validated for simpler test conditions. This study uses PIV to record the turbulent mixing of three adjacent naturally convective jets. The results are validated by comparing the PIV vector field with an ultrasonic flowmeter analytic flow rates. 


\section{TEST FACILITY}

Idaho National Laboratories (INL) supplied a $1 / 16^{\text {th }}$ geometrically scaled experimental facility as shown in Table 1 and Figure 1 . The reference is the Generation IV modular hightemperature gas-cooled reactor (MHTGR).

Table 1. Dimensions of scaled VHTR geometry provided by INL and nomenclature

\begin{tabular}{|c|c|c|c|}
\hline Variables & Nomenclature & "MHTGR (m) & $1 / 16^{\text {th }}$ scaled VHTR $(\mathrm{m})$ \\
\hline Bottom of the lower plenum & Reference & -2.88255 & 0 \\
\hline Bottom of the lower reflector & $\mathrm{L}_{\mathrm{RB}}$ & -1.9825 & 0.05625 \\
\hline Bottom of the core & $\mathrm{L}_{\mathrm{CB}}$ & 0.0 & 0.18016 \\
\hline Top of the core & $\mathrm{L}_{\mathrm{CT}}$ & 7.93 & 0.6758 \\
\hline Top of the upper reflector & $\mathrm{L}_{\mathrm{RT}}$ & 9.516 & 0.7749 \\
\hline Top of the upper plenum shield & $\mathrm{L}_{\mathrm{T}}$ & 12.6656 & 0.9718 \\
\hline Height of upper plenum & & 3.1496 & 0.197 \\
\hline Reactor vessel inner diameter & $\mathrm{D}_{\mathrm{RV}}$ & 6.534 & $0.4083(=16.07 \mathrm{in})$ \\
\hline Core barrel inner diameter & $\mathrm{D}_{\mathrm{CID}}$ & 5.95 & $0.370(=14.57 \mathrm{in})$ \\
\hline Coolant channel diameter & $D_{\text {Hole }}$ & 0.01588 & $0.01905(=0.75 \mathrm{in})$ \\
\hline Number of coolant channels & $\mathrm{N}_{\text {coolnat }}$ & 11000 5/8 inch diameter & 25 \\
\hline Coolant channel flow area $\left(\mathrm{m}^{2}\right)$ & A $_{\text {Coolant }}$ & $\begin{array}{r}2.177 \text { (considering only } \\
5 / 8 \text {-inch channels) }\end{array}$ & 0.00713 \\
\hline Coolant channel pitch & $\mathrm{P}$ & 0.0322 & $0.03861(=1.52 \mathrm{in})$ \\
\hline Pitch-to-Diameter ratio & $\mathrm{P} / \mathrm{D}_{\text {Hole }}$ & 2.03 & 2.03 \\
\hline
\end{tabular}




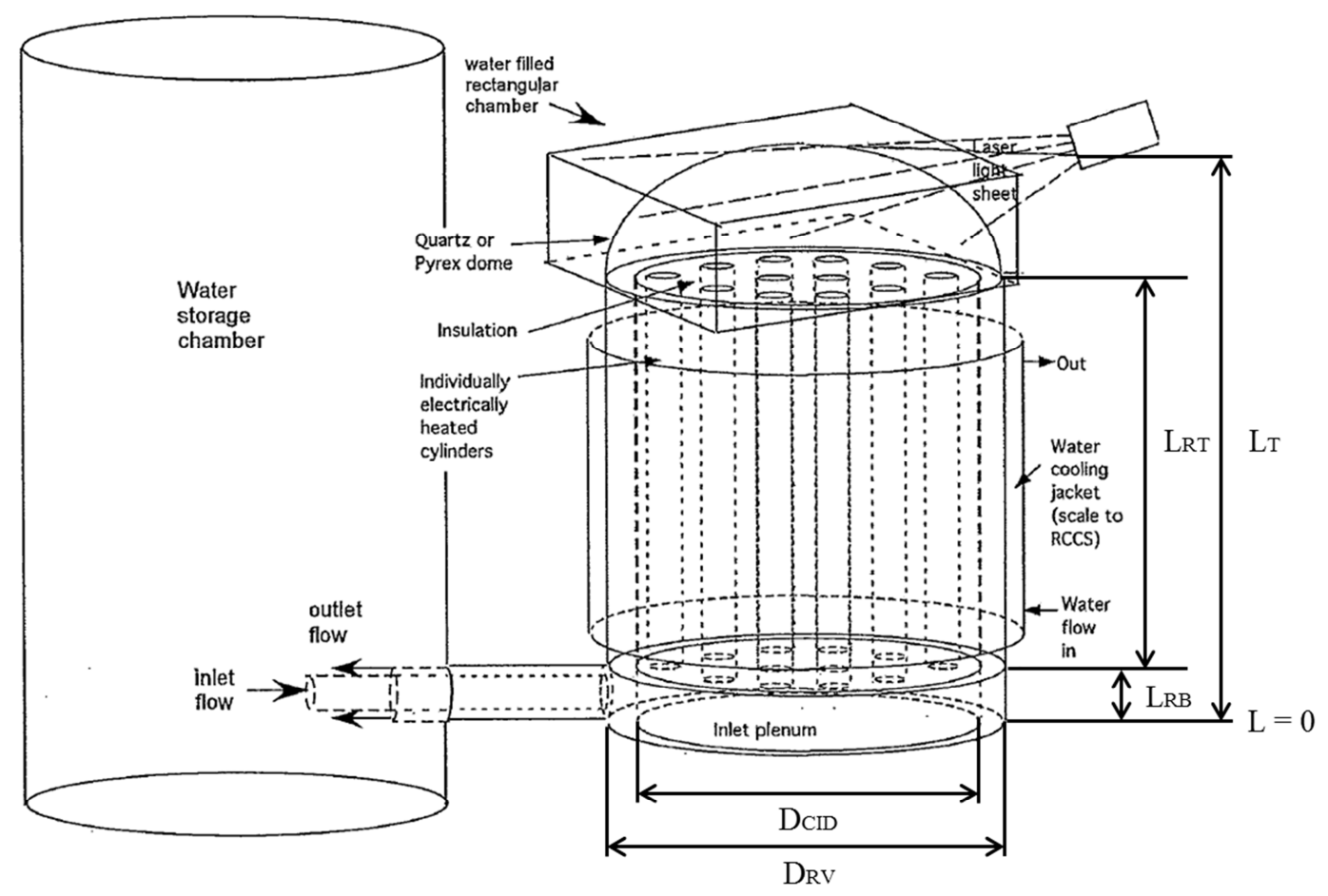

Fig. 1. The scaled VHTR design provided by INL

This experiment is a preliminary testing of the PIV system, but is designed to have the capabilities to produce benchmark data for DCC and PCC accident scenarios after reaching steady state. The prototype fuel decay heat is modeled with individually electrically heated cylinders. When scaling an experiment to model the natural circulation in the prototype plenums, the main approach is matching the Richardson number, the ratio of the buoyancy force to inertial force, and the Reynolds number, the ratio of inertial to viscous forces, for the model and the VHTR prototype [14]. This may be achieved once the systems have reached steady state. The Richardson ratio is shown in Equation (1).

$$
\mathrm{Ri}=\frac{g \beta \Delta T D}{V^{2}} \rightarrow \frac{\mathrm{Ri}_{m}}{\mathrm{Ri}_{p}}=\frac{\left(\frac{\Delta \rho}{\rho}\right)_{m}}{\left(\frac{\Delta \rho}{\rho}\right)_{p}} \frac{V_{p}^{2} D_{m}}{V_{m}^{2} D_{p}}
$$


The ratio is currently in terms of density, but the Boussinesq approximation may be applied to set the ratio in terms of temperature. The Boussinesq approximation relates the density variation to be a function of temperature rise, as shown in Equation (2).

$$
\begin{gathered}
\rho=\rho_{0}+\Delta \rho \rightarrow \Delta \rho=-\beta \rho_{0} \Delta T \\
\frac{\operatorname{Re}_{m}}{\operatorname{Re}_{p}}=\frac{V_{m} D_{m} v_{p}}{V_{p} D_{p} \nu_{m}}=\left[\frac{\left(\frac{\Delta \rho}{\rho}\right)_{m}}{\left(\frac{\Delta \rho}{\rho}\right)_{p}}\right]^{1 / 2}\left[\frac{D_{m}}{D_{p}}\right]^{3 / 2} \frac{v_{p}}{v_{m}}
\end{gathered}
$$

If the Richardson numbers match then the velocity ratio may be extracted from Equation (1). This may be substituted into the Reynolds number ratio to make the ratio a function of density variation or temperature rise shown in Equation (3). Using these ratios the independent variables of the experiment are determined. When modeling a DCC experiment, the independent variables would be the core heat input and distribution. For a PCC experiment a pump would be added, so the flowrate and core heat would act as the independent variables. Since this is just a preliminary testing maximum power was supplied to the active pipes. Since the model will be operating at much lower temperatures and pressures than the prototype, matching $\mathrm{Re}$ and $\mathrm{Ri}$ is not possible with the same working coolant. If the working coolant for the model was replaced with water, the density and viscosity for cold and hot water (approximately 20 and $46^{\circ} \mathrm{C}$ ) are appropriate to match the Richardson and Reynolds number of the high temperature and pressure helium in the prototype. 
Using the scaled geometry in Table 1 and Figure 1 a design for the experimental facility was generated, shown in Figure 2. The grey parts are polycarbonate, and the blue parts are stainless steel chosen for high thermal conductivity. The dimensions without the wall thickness of the geometry were matched with the INL provided ones. The diameter of the main coolant inlet and outlet are 1 in and 3 in, respectively with a length of $1.94 \mathrm{~m}$. The basis for the design was a closed loop system where the flow is driven purely by natural circulation. The coolant enters the lower plenum from the inlet pipe, and is drawn up through heated pipes by natural convection. The water then leaves the pipes as slow jets into the upper plenum, the region of interest. The water exits the upper plenum through the downcomer, the region between the core containment and outer containment. A heat sink would need to be built that removes heat as the flow goes through the downcomer to the outlet pipe of the system. The outlet pipe leads to a reservoir tank which then leads back to the inlet pipe completing the coolant loop. Next the pipe layout for the core was needed. Through collaboration with INL a final design of 25 pipes with a $1.905 \mathrm{~cm}$ inner diameter arranged in an octagonal pattern equidistant from each other was chosen, shown in Figure 3. Initially an annular pattern was considered, but was overruled as having the pipes be equidistant was priority. The pipes would be heated with heating tapes which were sorted in groups of five. These five groups would then be connected to five voltage variable transformers which could control the power to the heating tapes, and the resulting heat input. For this study, only T group was run for the tests. Multiple design parameters were considered during the design process, the largest being: waterproof access to the core for wiring, ease of assembly and disassembly, data acquisition, and fabrication limitations. 


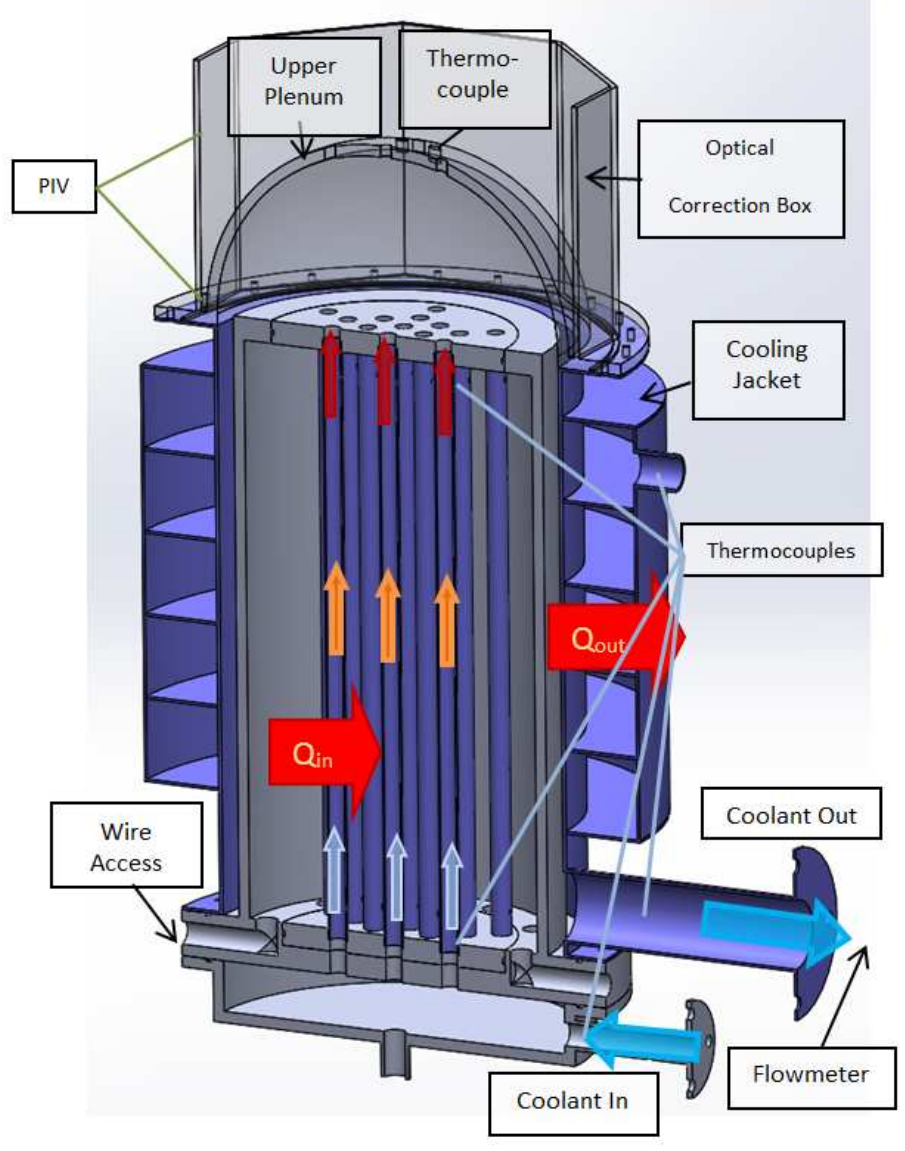

Fig. 2. Experimental facility schematic 


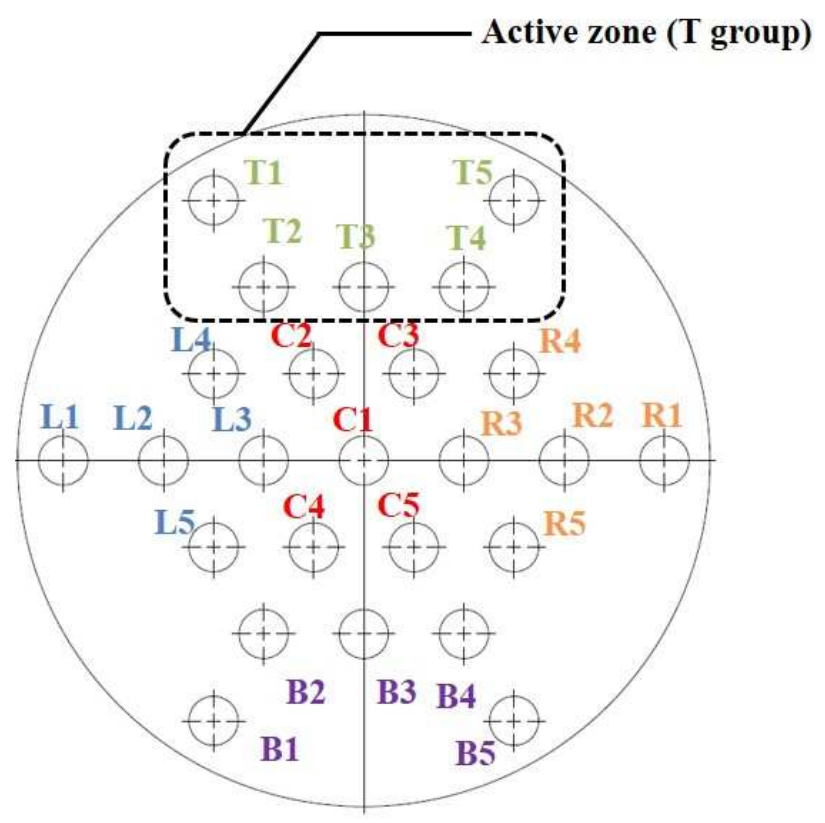

Fig. 3. Core piping

A heat sink is needed to remove the majority of the heat input to reach steady state and help induce natural circulation.. Since the DCC simulation is driven through natural circulation any large pressure drops in the system would inhibit the flow rate and the resultant data may not be representative. Instead an external non-intrusive cooling jacket was needed that would be connected to the outer containment and remove heat. The cooling jacket and reservoir removes sufficient heat from the system so that it may achieve steady state, without impacting the flow in the upper plenum where data is recorded. This effectively acts as the RCCS for the prototype. Because the reservoir is much larger than the test vessel, there would be no significant reservoir temperature rise during a test. To simulate a PCC scenario, an in-line heat exchanger is needed to remove sufficient heat to reach steady state. The final cooling jacket design shown in Figure 4 
has five rows of baffles. Water is pumped into the lowest baffle where it circles the containment and then rises $8.89 \mathrm{~cm}$. This process is repeated until it reaches the cooling jacket outlet.

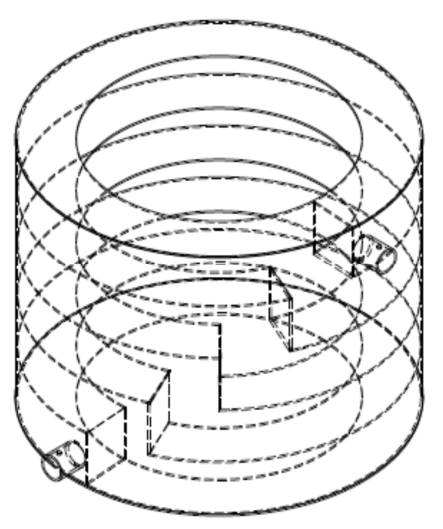

Fig. 4. Cooling Jacket Design

Figure 5 shows the assembly procedure. First the core containment and outer containment are lowered onto the lower plenum and their flange is bolted and sealed with O-rings. Next the core is assembled with the 25 pipes sealed into two plates with O-rings. The core is then dropped into the core containment where O-rings seal the plates with the containment. Finally the upper plenum is dropped and bolted onto the outer containment and sealed with either an O-ring or gasket. An arc welder was used to create T-type thermocouples which have an accuracy of \pm $0.5^{\circ} \mathrm{C}$, that were then calibrated using a certified thermometer with an accuracy of $\pm 0.3^{\circ} \mathrm{C}$, installed at the centerline of the core piping and test vessel inlet and outlet. The combined accuracy of the measured temperature was calculated by taking the square root of the sum of the squares and was estimated $\pm 0.58^{\circ} \mathrm{C}$. As shown in Figure 2 the thermocouples will measure the temperature rise for each pipe in the core, the temperature rise of the main coolant loop, and the 
temperature rise in the cooling jacket. The thermocouples enter the fluid through compression fittings, which are welded to the 25 pipes. To prevent leaks through the thermocouple locations, the thermocouples were inserted into fine steel tubing and both ends were sealed with UV epoxy as shown in Figure 6; this also protects the thermocouple tips from corrosion. There are nine ports for thermocouples in the upper plenum that may be inserted vertically above the pipe outlets to measure the temperature field. The thermocouples are connected to a National Instruments SCXI-1600 data acquisition system and measured with Labview. An ultrasonic flowmeter, Krohne Optisonic 6400, measures the outlet flow rate of the main coolant loop with an accuracy of $\pm 1 \%$ reading value for flow greater than $0.5 \mathrm{~m} / \mathrm{s}$, and a paddlewheel flowmeter measures the cooling jacket flow rate with an accuracy of $\pm 0.227 \mathrm{~L} / \mathrm{min}$. 


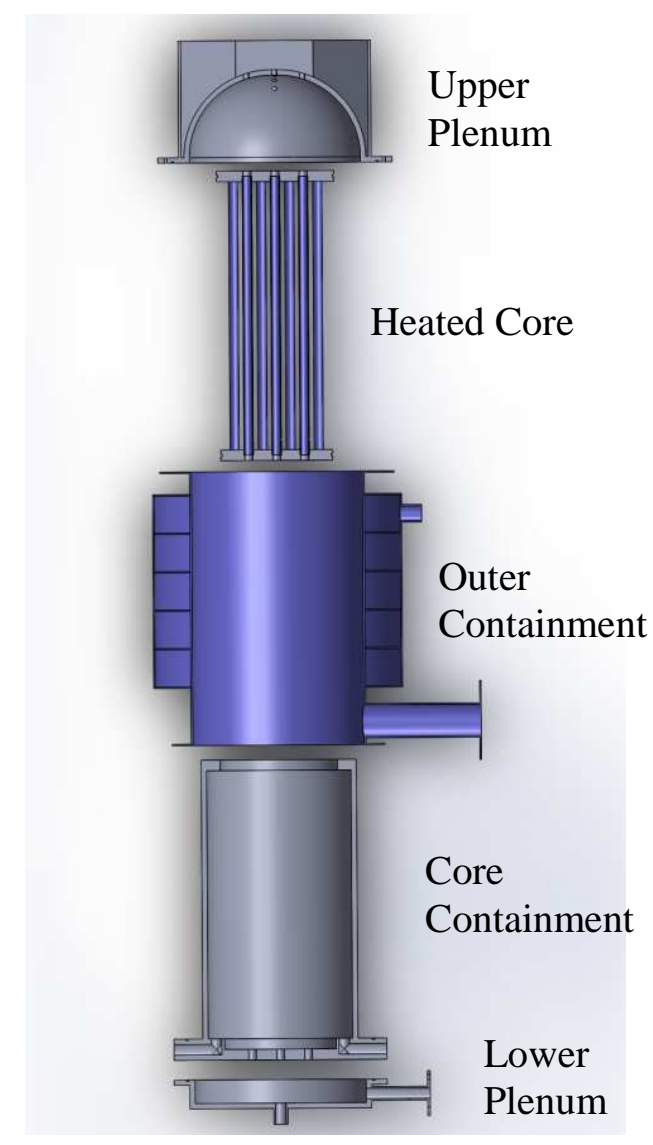

Fig. 5. Exploded assembly cross section

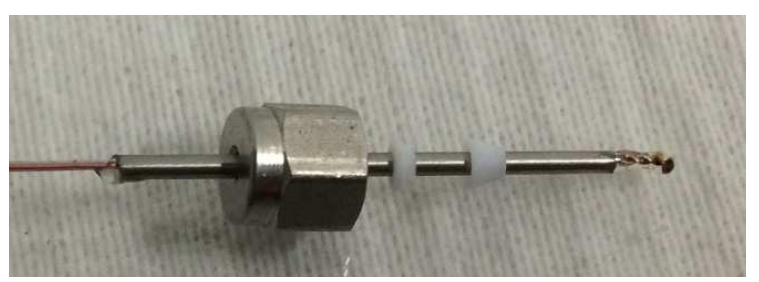

Fig. 6. Thermocouple with tubing, epoxy, and ferrules

PIV is used to measure a planar velocity field in the upper plenum. PIV involves seeding the working fluid with particles of equal density, and firing a laser sheet pulse that illuminates a plane of particles. The illuminated particles are then captured with a high speed camera in sync 
with the laser pulse; a sample is shown in Figure 7. Two laser pulses are fired in quick succession and both particle images are captured. A program then uses cross-correlation to track the patterns of particles between the two images, and using the time between the pulses a velocity vector field can be generated [15]. For this study a Vlite series dual laser pulse system was used, which operated at a wavelength of $532 \mathrm{~nm}$ with a pulse width of approximately $1 \mathrm{~mm}$. A high speed camera MEMRECAM GX-3 was used for the imaging, and connected to the laser with a waveform generator. A lens Zeiss 2/50 Makro-Planar ZF.2 Macro Lens was used for the test. For the particle seeding fluorescent orange polyethylene microspheres were used. Their diameter ranged from 53-63 $\mu \mathrm{m}$, and had a density of $1.002 \mathrm{~g} / \mathrm{cm}^{3}$. Fluorescent particles reflect the laser light at a different wavelength, so an optical filter was used for the camera that blocked the wavelength of the laser and consequently removing all light noise and producing clear particle images. As shown in Figure 2 a correction box is built around the upper plenum; when a curved surface is filled with water there is an optical distortion caused by refraction. The correction box presents a flat viewing plane, and the medium between the plane and curved surface is filled with water so that the images may be recorded on a flat surface without refraction. An optical test was performed in Figure 8 to confirm there were no distortions. The heating tapes were sealed individually with silicon tubing for waterproofing and insulation. Figure 9 shows the completed test facility. 


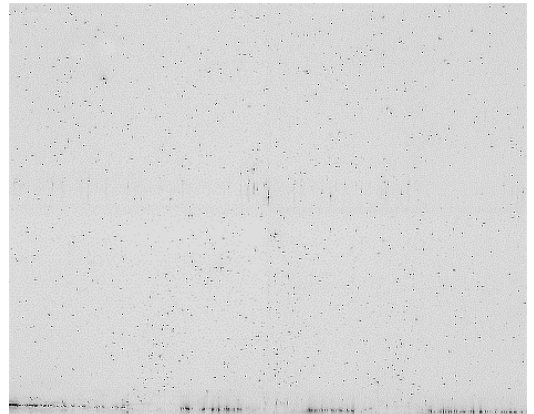

Test 1

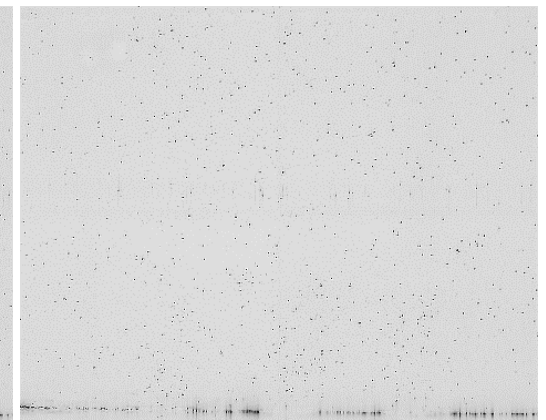

Test 2

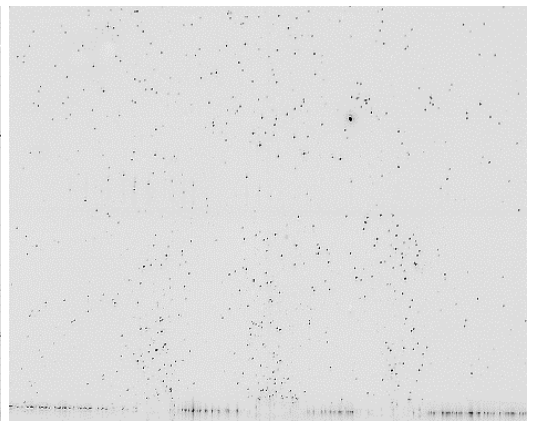

Test 3

Fig. 7. Particle images for PIV analysis with black and white inversion

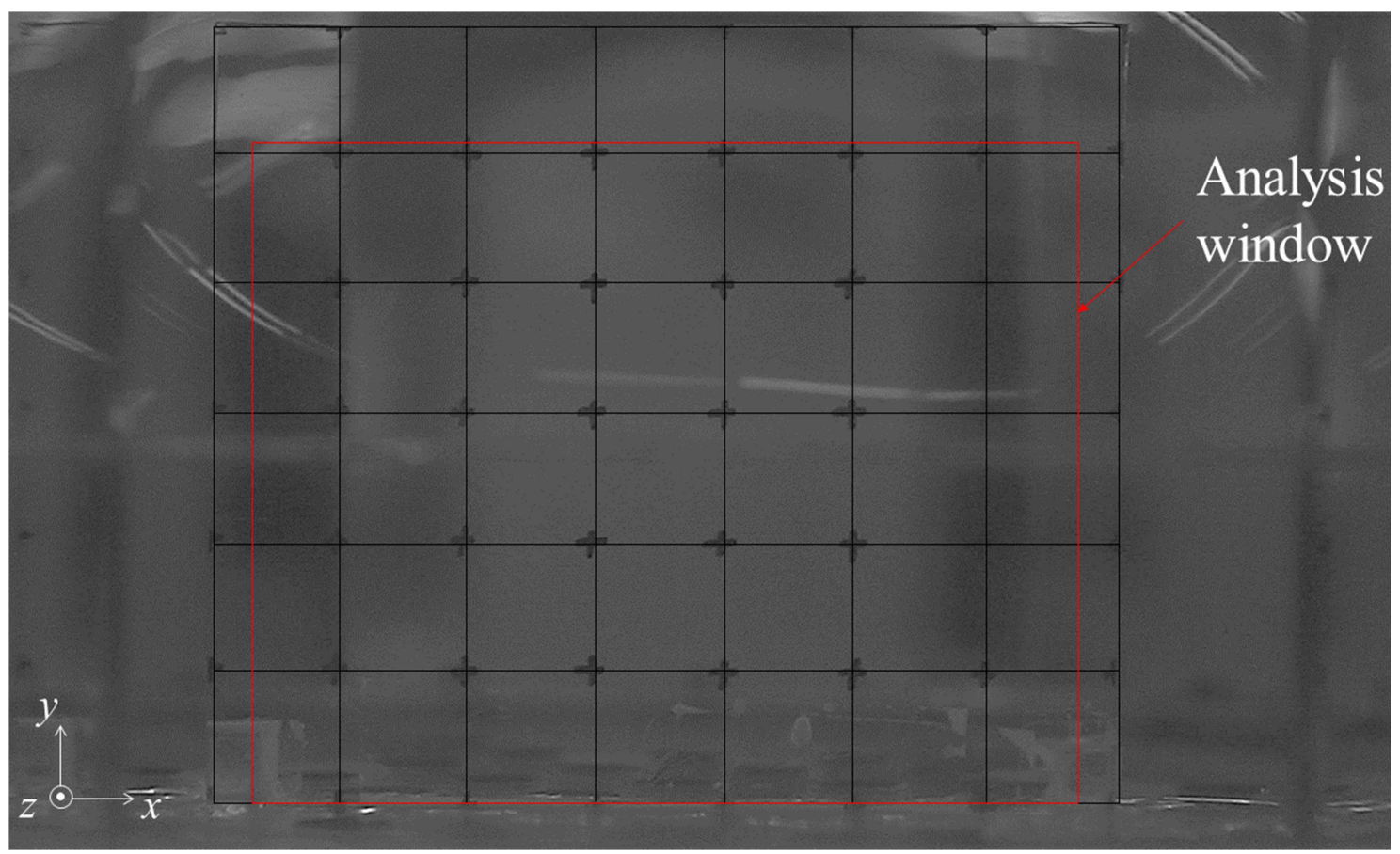

Fig. 8. Optical distortion test 

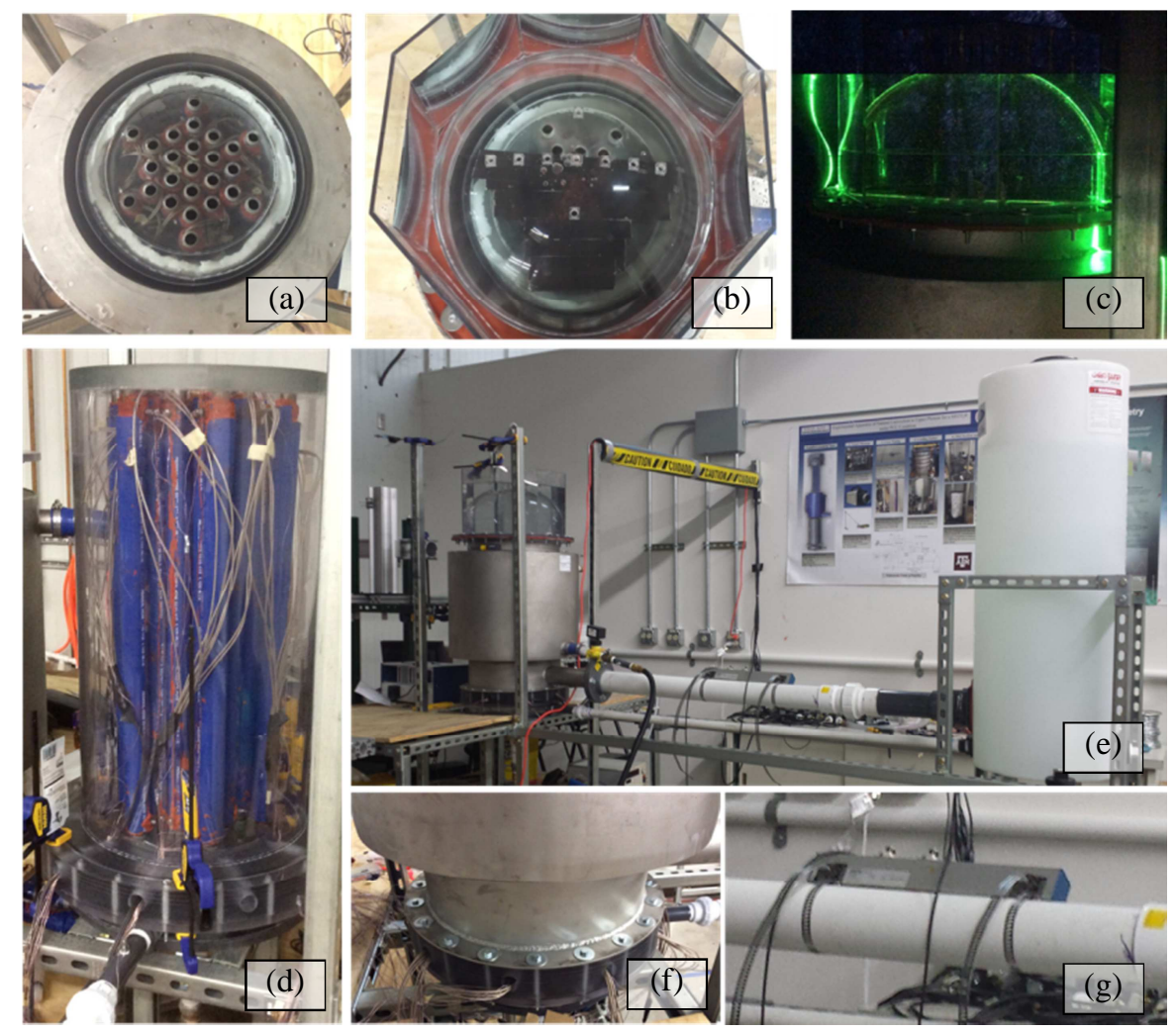

Fig. 9. Completed Test Facility: (a) Core top view (b) Upper plenum top view (c) Upper plenum during PIV (d) Core assembly (e) Full Assembly (f) Core wire access (g) Ultrasonic flowmeter 


\section{EXPERIMENT}

The system was run at partial core power to test the validity of the PIV process and capabilities of the test facility. Power was supplied only to the five pipes in T-group from Figure 3 , and the other pipes were sealed off. A total of $1.44 \mathrm{~kW}$ power was evenly distributed between the five heating tapes for this preliminary test to run the maximum capability of the current test facility. The camera was positioned to capture a $16 \times 13 \mathrm{~cm}$ window above the outlets of three adjacent natural convection jets, shown in Figure 10. The laser sheet is aligned with marked locations on the test facility, and adjusted for the optimal power output. The laser used was a Vlite-200 from Beamtech Optronics Co. It has an average beam thickness of $1 \mathrm{~mm}$, and can provide up to $200 \mathrm{~mJ}$ per pulse; we used $60 \mathrm{~mJ}$. The test heaters were left on, and the cooling jacket was turned on to approximately $41.5 \mathrm{~L} / \mathrm{min}$, the maximum flowrate of the local water supply. The test vessel and reservoir were filled with room-temperature water, and then the heaters and cooling jacket were activated. Steady state was determined when the outlet temperature rise across the core was $25^{\circ} \mathrm{C}$ to $45^{\circ} \mathrm{C}$, and the temperature rise of the test vessel remained near $25^{\circ} \mathrm{C}$ and constant for five minutes. Next the particles were injected into the test vessel inlet pipe, and allowed to circulate into the upper plenum. At steady state the coolant outlet temperature of the vessel after passing through the cooling jacket was within $0.5^{\circ} \mathrm{C}$ of the reservoir temperature ensuring there would be no significant temperature rise in reservoir that would impede the system reaching steady state. Additionally the low flow rates and large piping resulted in a very low pressure drop to and from the reservoir so flow was not impeded. Once steady state was achieved the particles were injected at the inlet of the test facility, and particle images were collected. The test length was limited by the camera memory, which could hold up 
to 2,300 images. Because the fluid velocity was low, the camera and laser were synchronized to record images at $10 \mathrm{~Hz}$, which means that time interval of successive images $(\Delta t)$ was $0.1 \mathrm{~s}$; the test was run for approximately 4 minutes. The temperature of the system was constant within \pm $0.5^{\circ} \mathrm{C}$ once the system achieved steady state, and recorded with thermocouples at $1 \mathrm{~Hz}$. 

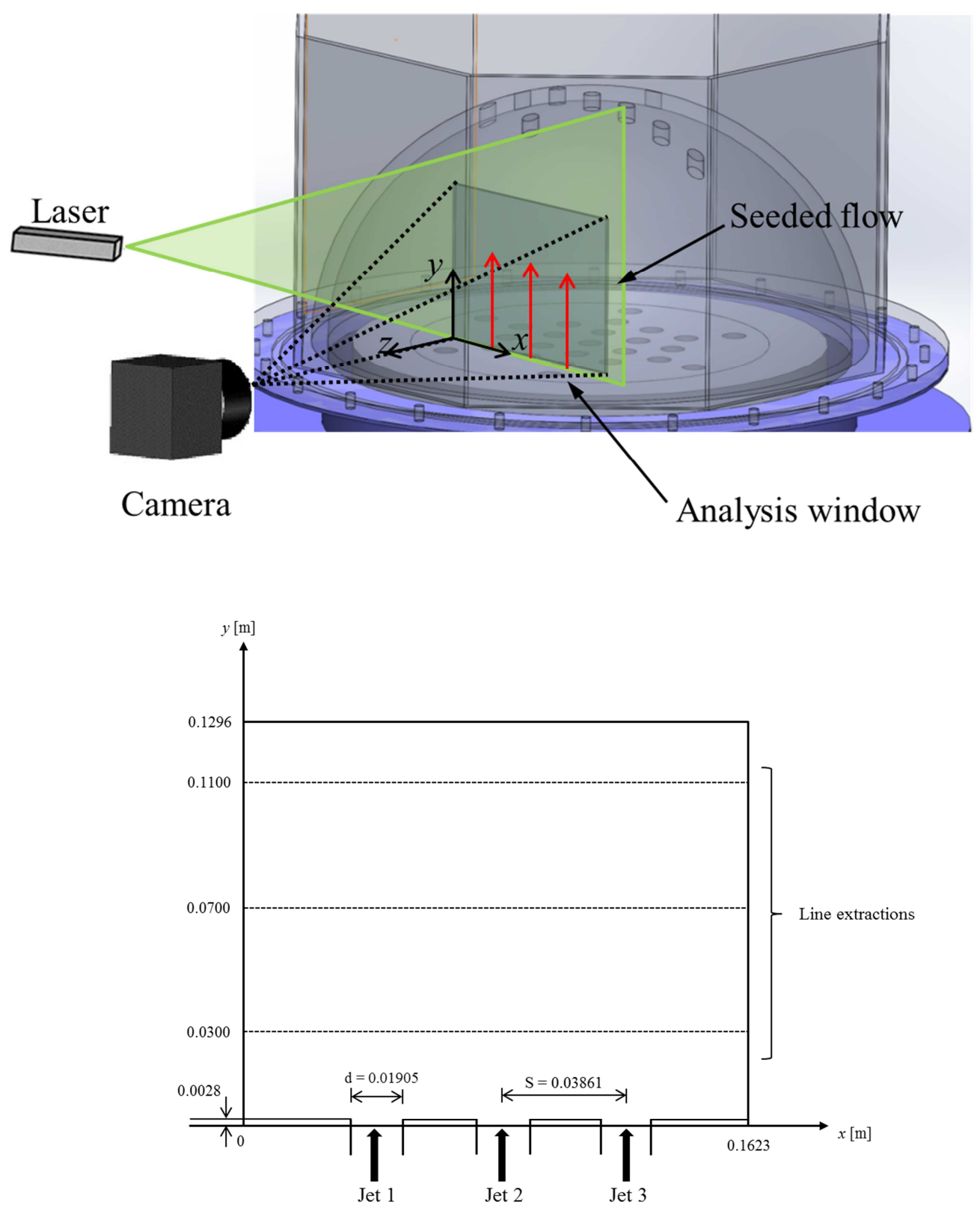

Fig. 10. PIV schematic and analysis window geometry

While the test was running the Krohne Optisonic 6400 ultrasonic flowmeter was measuring the total flow rate of the main coolant loop. The flowmeter had a $1 \%$ reading value accuracy for larger flow rates, but had no in-situ calibrations at the low operating flow rate of the 
system. A Krohne Optiflux 1000 electromagnetic flowmeter was installed on a nearby system and validated with an accuracy of $\pm 3 \%$ reading value at the operating low flow rate. A electromagnetic flowmeter is more accurate than an ultrasonic flowmeter due to the different measuring principle it employs. Because the flowmeter was in use, and could not operate on the 3" diameter pipe, the electromagnetic flowmeter was used to calibrate the ultrasonic flowmeter. The ultrasonic recorded flow for seven minutes and averaged the values, the average was then compared to the flow rate of the Optiflux reading. This was performed at six different low flow rates. The calibration formed a linear trendline shown in Figure 11, and the trendline equation was used to correct all test measurements.

The images were processed using PIVlab (version 1.32). PIVlab is an open source Matlab-based package developed by Thielicke and Stamhuis [16] and has been verified by several investigators [17-21]. The 2,300 images were imported in a first-second, third-fourth image pair manner so approximately 1,150 image pairs or frames were available.

The analysis window was $16 \times 13 \mathrm{~cm}$ with a $1280 \mathrm{x} 1024$ high resolution, and a $0.125 \mathrm{x}$ $0.127 \mathrm{~mm} /$ pixel size. Including the time between images, $1 \mathrm{px} /$ frame corresponds to $1.26 \mathrm{~mm} / \mathrm{s}$. When the particles are illuminated by the laser they occupy $4 \times 4$ pixels. When running PIV three interrogation windows were evalutated: $64 \times 64,32 \times 32$, and $16 \times 16$, and a step width of 32,16 , and 8 pixels respectively. The average particle shifted 65 pixels in one image pair. The calculated Stokes number of the seeding particles was calculated to be 0.0014 at the worst, confirming the seeding particles followed the fluid flow accurately [22]. After calculating the velocity vectors for each image pair, PIVlab runs an algorithm with that located erroneous vectors with a user input standard deviation threshold value (7) and replaced them with the mean value of the neighboring vectors, the details may be found in the cited document [16]. 


\section{Flowmeter Calibration Curve}

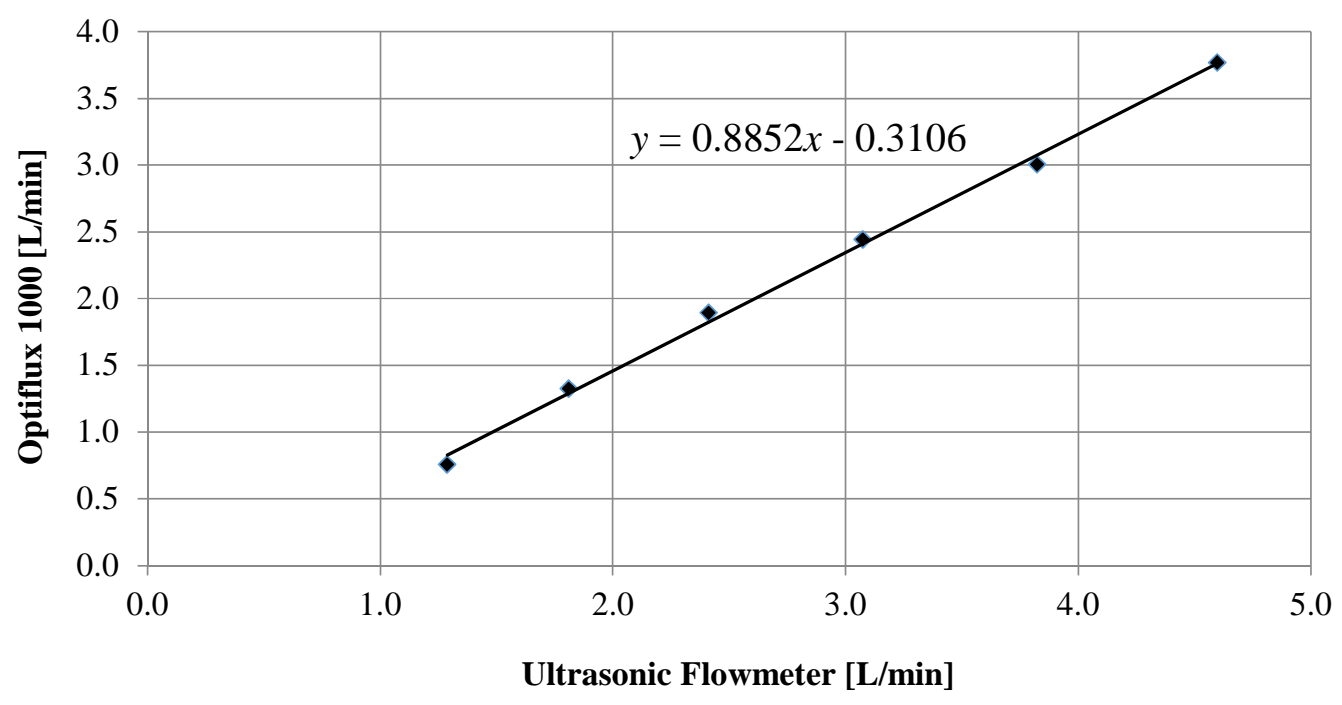

Fig. 11. Flowmeter calibration line 


\section{RESULTS AND ANALYSIS}

The turbulent velocity field fluctuates transiently, but statistically steady state may be measured by averaging the velocity for a batch of frames. This is shown in Equation (4),

$$
\boldsymbol{v}(r, t)=\overline{\boldsymbol{v}(r)}+\boldsymbol{v}^{\prime}(r, t)
$$

where the instantaneous velocity $v$ is represented as the averaged velocity $\bar{v}$ and the velocity fluctuation $v^{\prime}$. In order to validate the results multiple tests need to be run. A total of three tests were run for statistically steady state (Test 1 , Test 2 , and Test 3 ). One thousand frames were averaged to achieve the representative averaged velocity field over a duration of 200 seconds. The averaged velocity magnitude contour and streamlines are shown in Figure 12. There is a distortion 7 centimeters from the pipe outlets, this is due to the glued section between the curved dome and the cylinder in the upper plenum which slightly blurs the image and makes the particles harder to track. At $1 \mathrm{~cm}$ from the pipe outlet the contour is representative of the experimental flow. There is slight recirculation between the jets very close to the pipe outlet. The jets begin to merge approximately $3 \mathrm{~cm}$ from the pipe outlet, but diverge as the flow approaches the top of the test geometry which is exhibited by the streamlines. The $\mathrm{x}$ and y-velocity contours are shown in Figures 13 and 14 respectfully. Figure 13 shows that far from the pipe outlet the flow begins moving horizontally towards the downcomer. Figure 14 shows that the flow is predominantly vertical as the y-velocity contour nearly matches the velocity magnitude contour. Figure 15 shows the averaged vorticity contour, calculated from Equation (5). 


$$
\omega=\frac{\partial v}{\partial x}-\frac{\partial u}{\partial y}
$$

A single frame produces an instantaneous flow with eddies, but once averaged the results show good anti-symmetry. Directly between the jets the vorticity fluctuates such that the averaged value is approximately zero. 


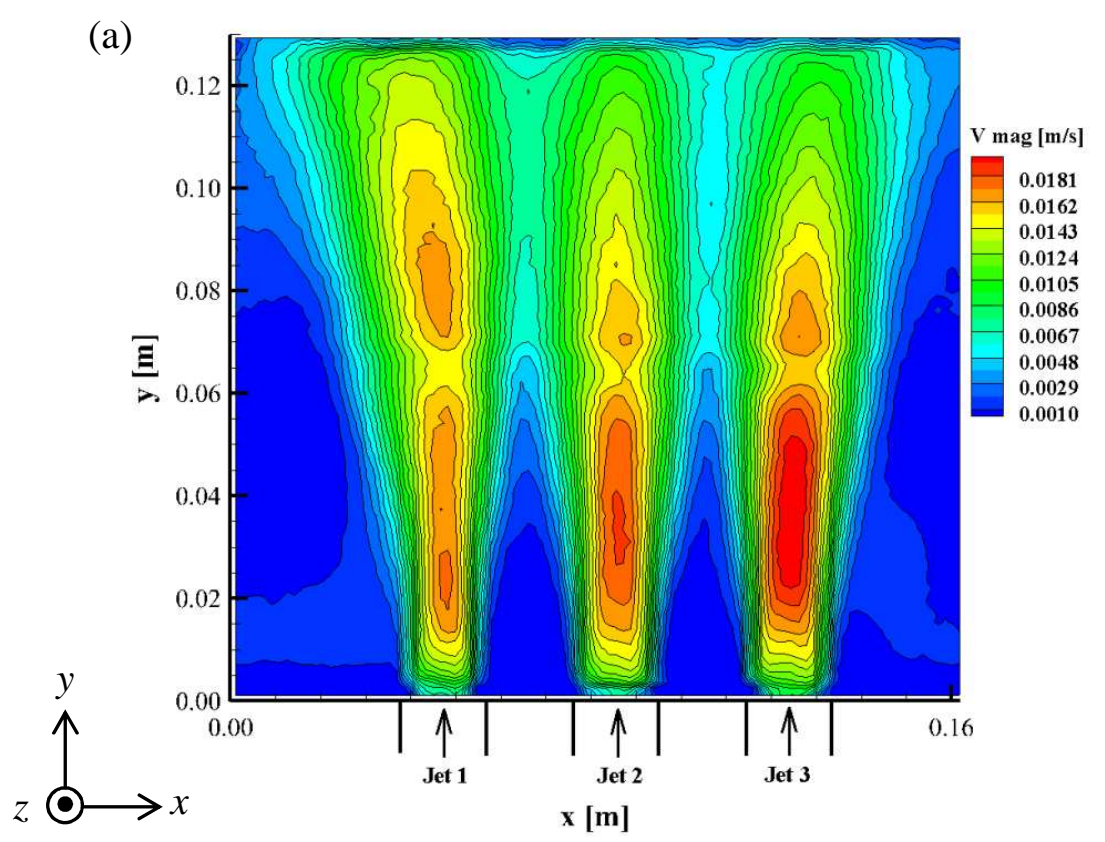

(b)

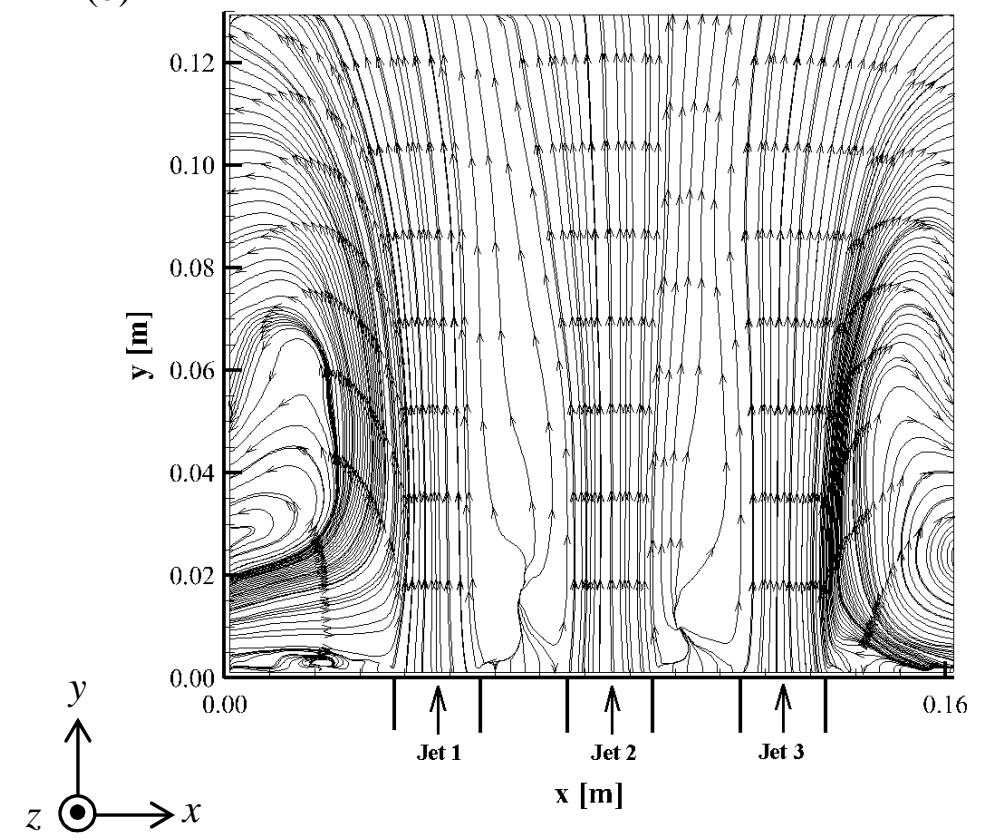

Fig. 12. (a) Velocity magnitude contour and (b) streamline of 1000 frames 


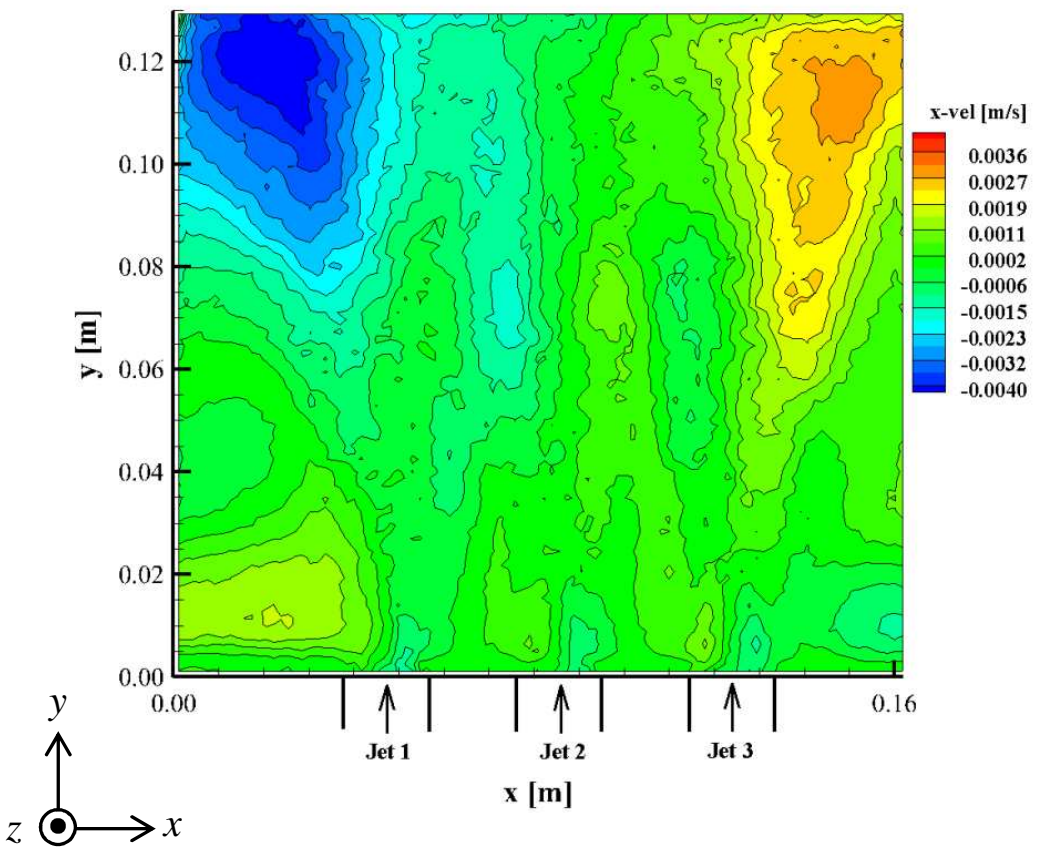

Fig. 13. $x$-velocity contour of 1000 frames

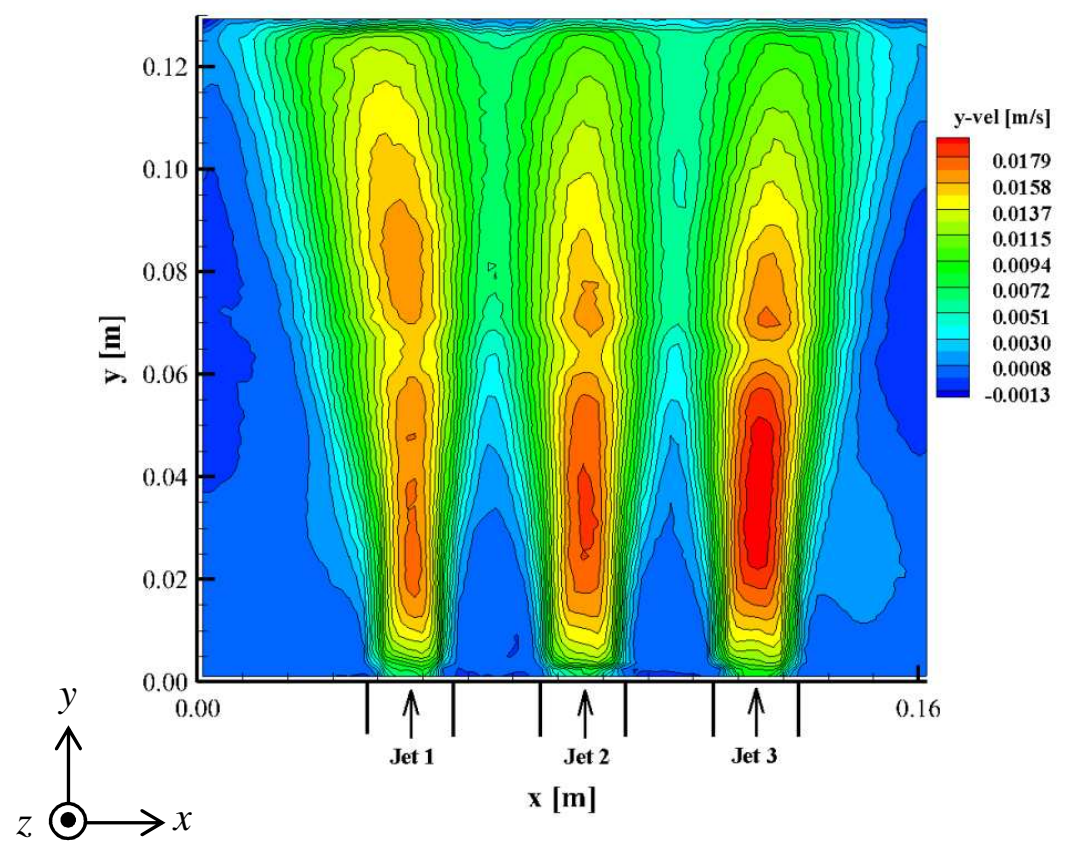

Fig. 14. y-velocity contour of 1000 frames 


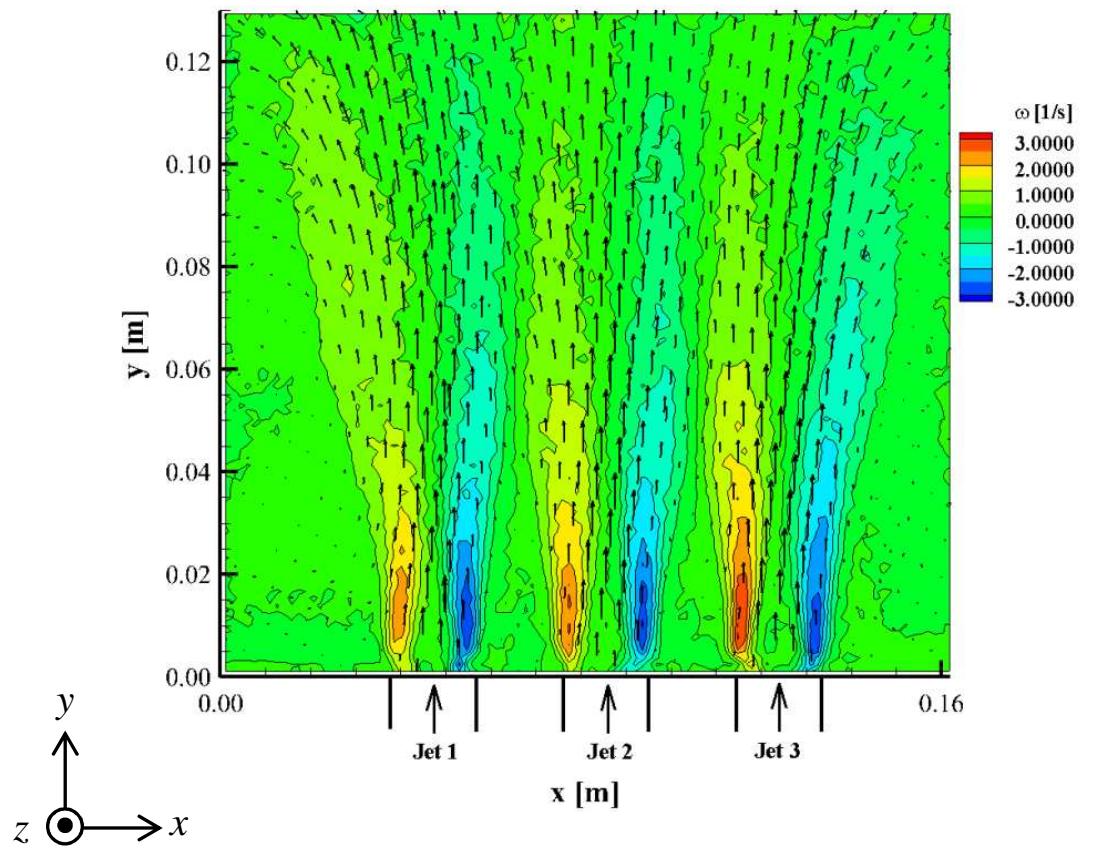

Fig. 15. Vorticity contour and average velocity vector of 1000 frames

First a sensitivity analysis must be performed to confirm a sufficient number of frames were used to correctly model statistically steady state; a similar analysis was performed by Amini and Hassan [23]. To do this, different batch sizes of frames were used to calculate the averaged velocity field and this was compared to the previous averaged velocity field; as the batch sizes increase the flow profiles should began to match. The root-mean-square (RMS) deviation was calculated using Equation (6),

$$
\text { Error }=\sqrt{\frac{\sum_{i, j=1}^{n}\left(v_{i, j}^{k}-v_{i, j}^{k-1}\right)^{2}}{N}}
$$


where $v_{i, j}^{k}$ represents the averaged y-velocity field $(i, j)$ at current frame count $(k), v_{i, j}^{k-1}$ represents the averaged $\mathrm{y}$-velocity field $(i, j)$ at previous frame count $(k-1)$, and $\mathrm{N}$ is the current number of frames $(k)$. This was run for all 159x127 vectors from PIVlab using the Fast Fourier Transform (FFT) option, the results are shown in Figure 16. As the batch sizes increase errors continue to decrease constantly and reach less than $5.0 \times 10^{-4}$ after the 700 frames average, confirming that 1,000 frames are sufficient to measure statistically steady state. Tests 1 and 2 converge as expected, but Test 3 converges abnormally implying that the results may be misrepresentative of the flow and will not be shown in this study. It is hypothesized that this occurred because insufficient time was allowed to let the particles circulate through the system for test 3.; Figure 7 shows the particle density difference between the tests.

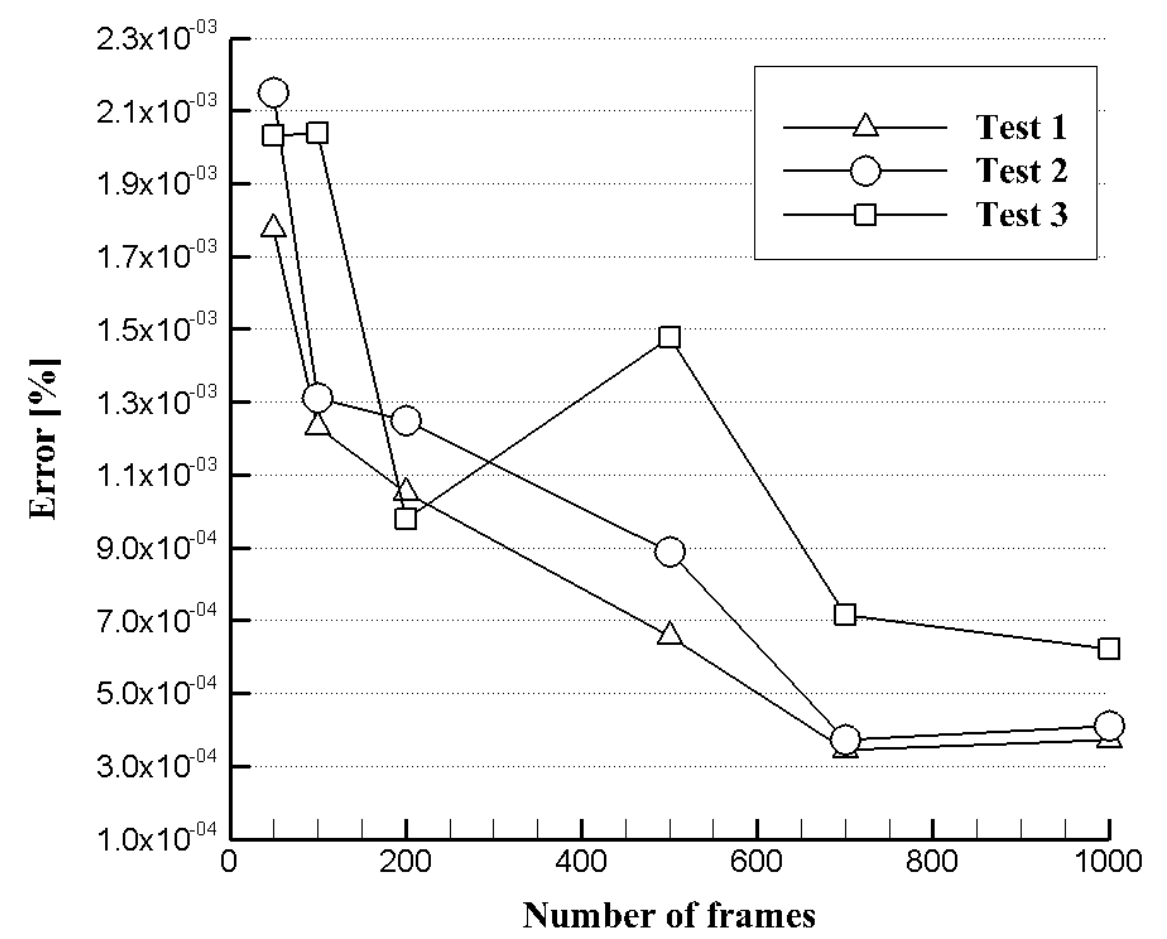

Fig. 16. Percent error of y-velocity field for different batch sizes of frames 
Additionally the y-velocity was extracted at 3,7 and $11 \mathrm{~cm}$ from the pipe outlet for different batch sizes. Note that each symbols represents following numbers of frames: 50 frames $(\circ), 200$ frames $(\nabla), 500$ frames $(\bullet)$ and 700 frames $(\nabla)$. The solid line is the velocity for 1000 frames and is used as reference. At $3 \mathrm{~cm}$ Figures 17 and 18 show the majority of the batch sizes match the reference. At $7 \mathrm{~cm}$ Figures 19 and 20 show that the 50 and 200 batch sizes begin to differ significantly from the reference. Additionally the jets began merging. At $11 \mathrm{~cm}$ Figures 21 and 22, 500 and 700 frames begin to differ slightly, primarily in Test 1 . This suggests when modeling significantly far from the pipe outlet to correctly represent the flow field more images need to be processed. Also the jets continue to merge, but stays within the merging region. The analysis window for this study is too small for the jets to fully merge and reach the combined point.

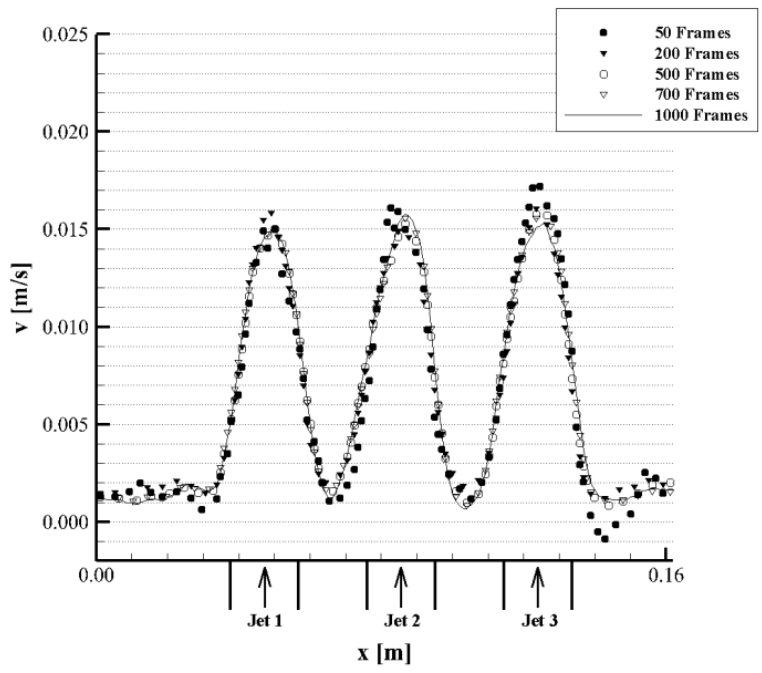

Fig. 17. Test 1 sensitivity analysis at $3 \mathrm{~cm}$ from pipe outlet

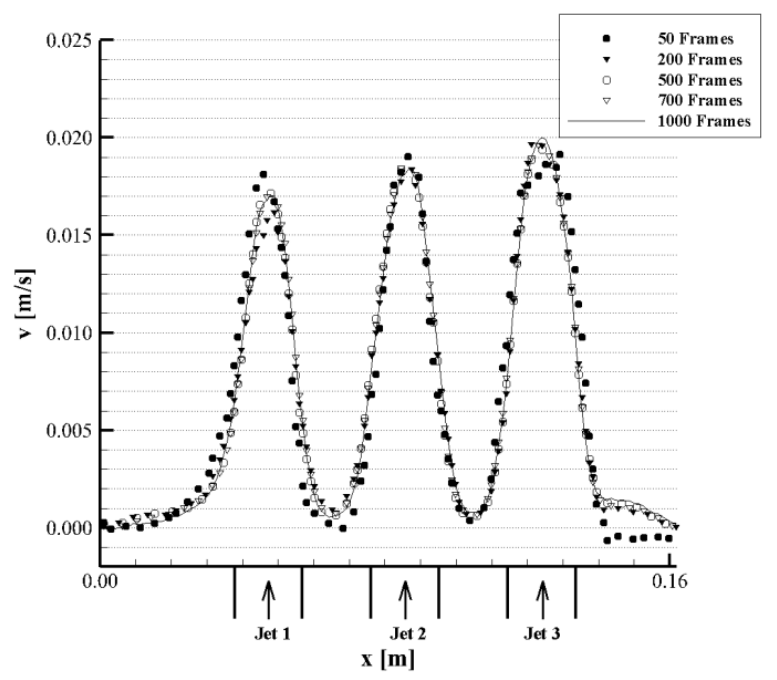

Fig. 18. Test 2 sensitivity analysis at $3 \mathrm{~cm}$ from pipe outlet 


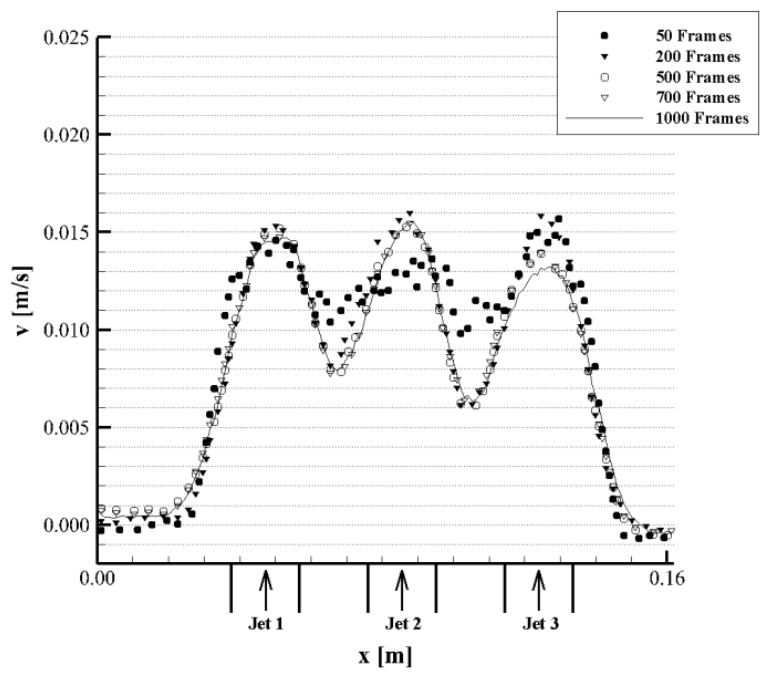

Fig. 19. Test 1 sensitivity analysis at $7 \mathrm{~cm}$ from pipe outlet

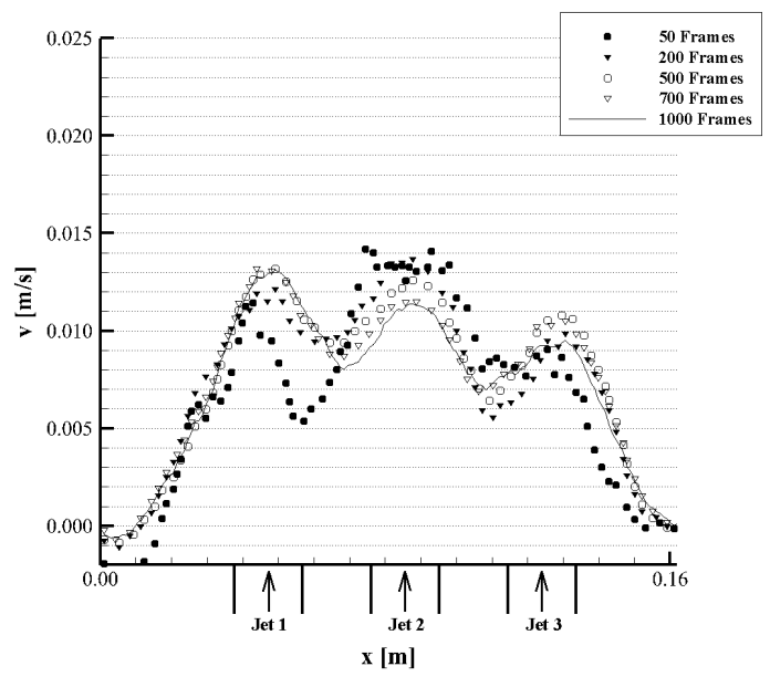

Fig. 21. Test 1 sensitivity analysis at $11 \mathrm{~cm}$ from pipe outlet

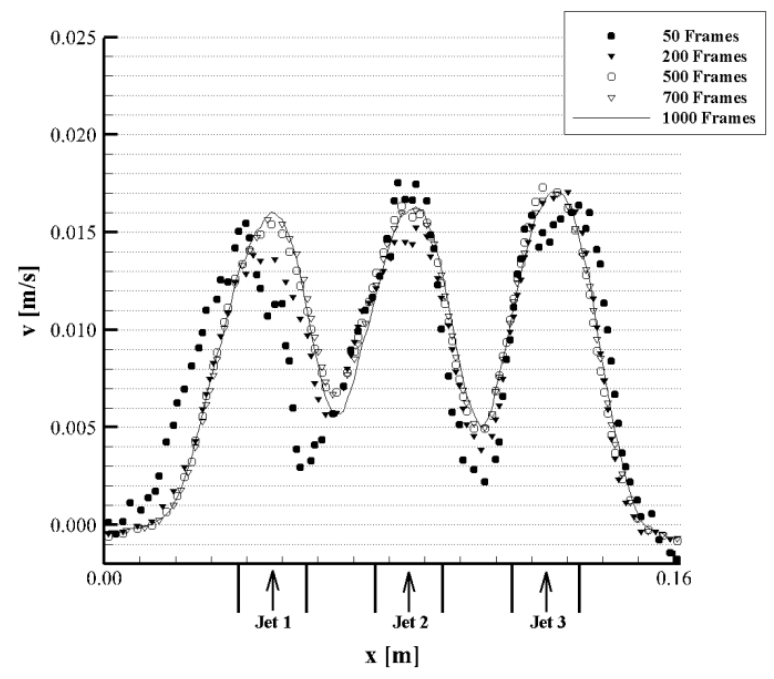

Fig. 20. Test 2 sensitivity analysis at $7 \mathrm{~cm}$ from pipe outlet

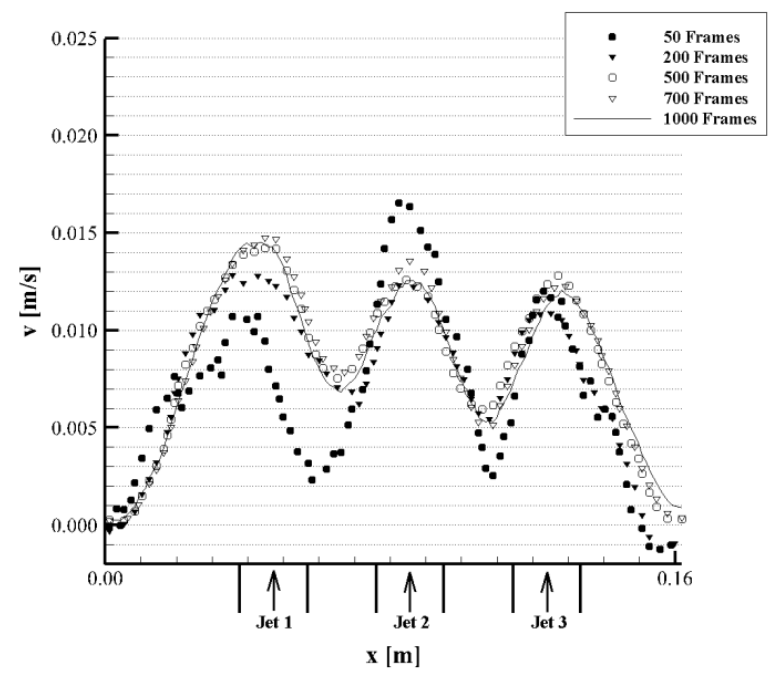

Fig. 22. Test 2 sensitivity analysis at $11 \mathrm{~cm}$ from pipe outlet

Equation (7) was used to average the velocity profile for the 1,000 frames $(N)$ for each test, and average the velocity profile between the tests $(M=2)$. The uncertainty was generated by 
standard deviation between the tests. Figure 23 shows that there is uncertainty between the tests; to more accurately assess the repeatability, more tests need to be run.

$$
v_{\text {ave }}=\frac{1}{M} \sum_{m=1}^{M}\left(\frac{1}{N} \sum_{k=1}^{N} v_{m}^{k}\right)
$$

Once the jets enter the upper plenum mixing occurs which causes the flow to become turbulent. The turbulence strength can be calculated by taking the root mean square (rms) of the velocity over a period of time, shown in Equation (8).

$$
v_{r m s}=\frac{1}{M} \sum_{m=1}^{M} \sqrt{\frac{\sum_{k=1}^{N}\left(v_{m}^{k}-\bar{v}_{m}^{N}\right)^{2}}{N}}
$$

The turbulent intensity (TI) can be calculated by dividing the averaged velocity $\left(v_{\text {ave }}\right)$ from the turbulence strength $\left(v_{r m s}\right)$. Figure 24 shows the turbulence strength averaged between Test 1 and 2. The turbulent strength is largest inside the jets where the mixing occurs, and the resulting TI is approximately $41 \%$ of the peak velocity, meaning $\mathrm{TI}=0.4$ in the jets. This shows that the flow goes turbulent in the upper plenum where the mixing occurs, but less so between the jets. TI increases to $45 \%$ at the jet velocity peak $11 \mathrm{~cm}$ from the pipe outlet. 


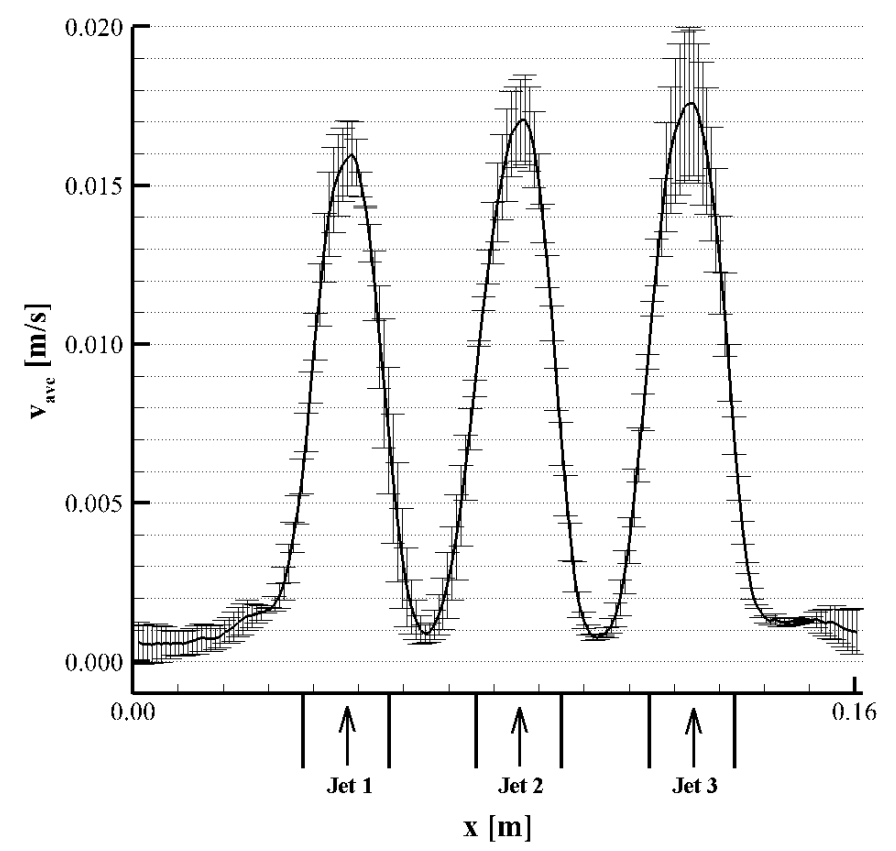

Fig. 23. Averaged y-velocity at $3 \mathrm{~cm}$ from the pipe outlet with standard deviation between the tests

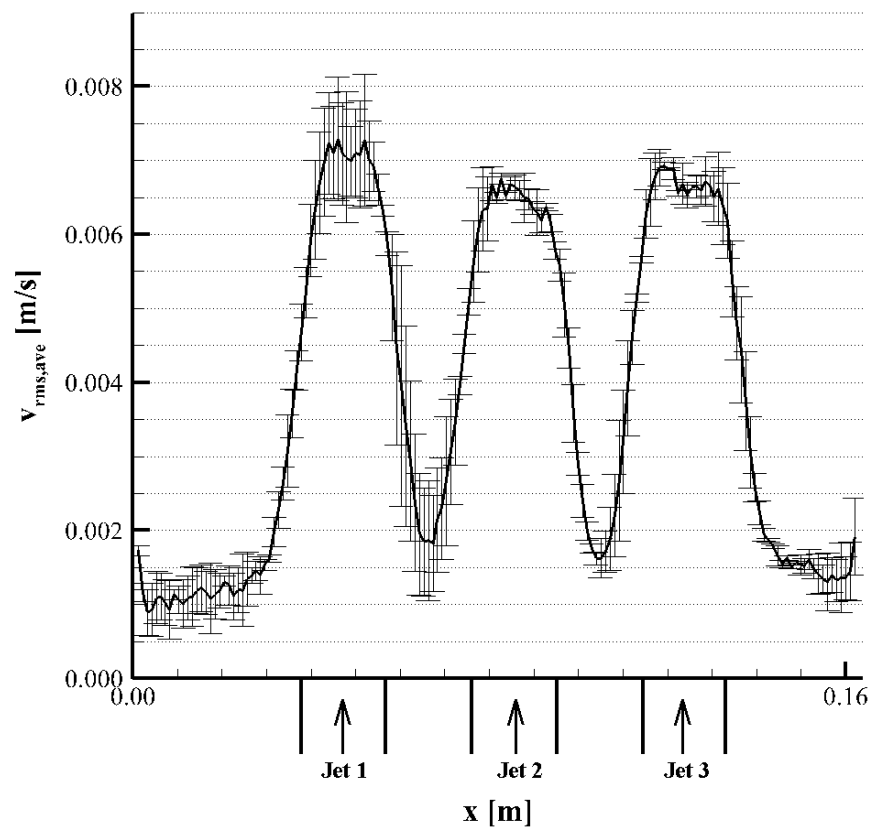

Fig. 24. Averaged turbulence strength at $3 \mathrm{~cm}$ from the pipe outlet with standard deviation between the tests 
Next to validate the PIV results, the averaged flow rate for a single pipe is measured using the statistically steady state velocity vector field, and compared to an analytic flow rate and the ultrasonic flowmeter data. The flow rate of a single pipe may be calculated analytically using the heat balance equation as shown in Equation (9),

$$
\dot{m}=\frac{Q}{c_{p} \Delta T}
$$

where $Q$ is the heat input (W) from the heating tape, $\dot{m}$ is the mass flow rate $(\mathrm{kg} / \mathrm{s}), c_{p}$ is the specific heat capacity for water $(\mathrm{J} / \mathrm{kg} \cdot \mathrm{K})$, and $\Delta T$ is the temperature rise in the core piping $(\mathrm{K})$. $Q$ is controlled with the variable voltage transformer and the pre-measured resistance of the heating tape, and the temperature rise in the core is measured with thermocouples. At the steady state temperatures (approximately $25^{\circ} \mathrm{C}$ and $45^{\circ} \mathrm{C}$ ) the specific heat matches, and there is minimal heat loss due to the insulating tubing. While the tests are running the ultrasonic flowmeter records the total flow rate of the system. The flow rates for all three methods are plotted in Figure 25. The analytic flow rate uncertainty is due to the error of the T-type thermocouples. From Equation (9), the error propagates to Equation (10). It was determined that the uncertainty from using centerline temperature rise over mean temperature rise is negligible compared to the RMS deviation of the thermocouples.

$$
\xi_{\dot{m}}=\sqrt{\left(\frac{d \dot{m}}{d T_{i}}\right)^{2}{\sigma_{T i}}^{2}+\left(\frac{d \dot{m}}{d T_{o}}\right)^{2}{\sigma_{T o}}^{2}}=\sqrt{\left(\frac{Q}{c_{p}} \frac{1}{\left(T_{o}-T_{i}\right)^{2}}\right)^{2} 0.58^{2}+\left(\frac{Q}{c_{p}} \frac{1}{\left(T_{o}-T_{i}\right)^{2}}\right)^{2} 0.58^{2}}
$$

The ultrasonic flowmeter uncertainty was set to $3 \%$, the error of the Optiflux electromagnetic flowmeter it was calibrated with. The three jets evaluated in the preliminary test have identical geometry and heating, meaning the flow rate for each jet should be equal. When the test facility 
is under full operation, the jet flow rates vary depending on the location of the pipe due to mixing and other phenomena, however under partial operation there is insufficient mixing to inhibit flow. To evaluate the accuracy of the jets having matching flow rates, the velocity vectors at a jet outlet generated by PIV analysis were averaged and then multiplied with area and density to calculate flow rate; this was performed for all three jets. The uncertainty for the flow rates calculated from the PIV data is the standard deviation of these three jet flow rates. This assumes axisymmetric behavior for the jet; the accuracy of this assumption is a limitation for the present study. The uncertainty of the PIV system will be calculated with a different method. All uncertainties are shown in Table 2. The flow rates for all three methods (Analytic flow rate using Equation (9), Ultrasonic flowmeter, and PIV) match closely for Tests 1 and 2. The uncertainties for Test 3 do not overlap, which was shown to be irregular from the sensitivity test and thus cannot be validated to be representative of the flow. 


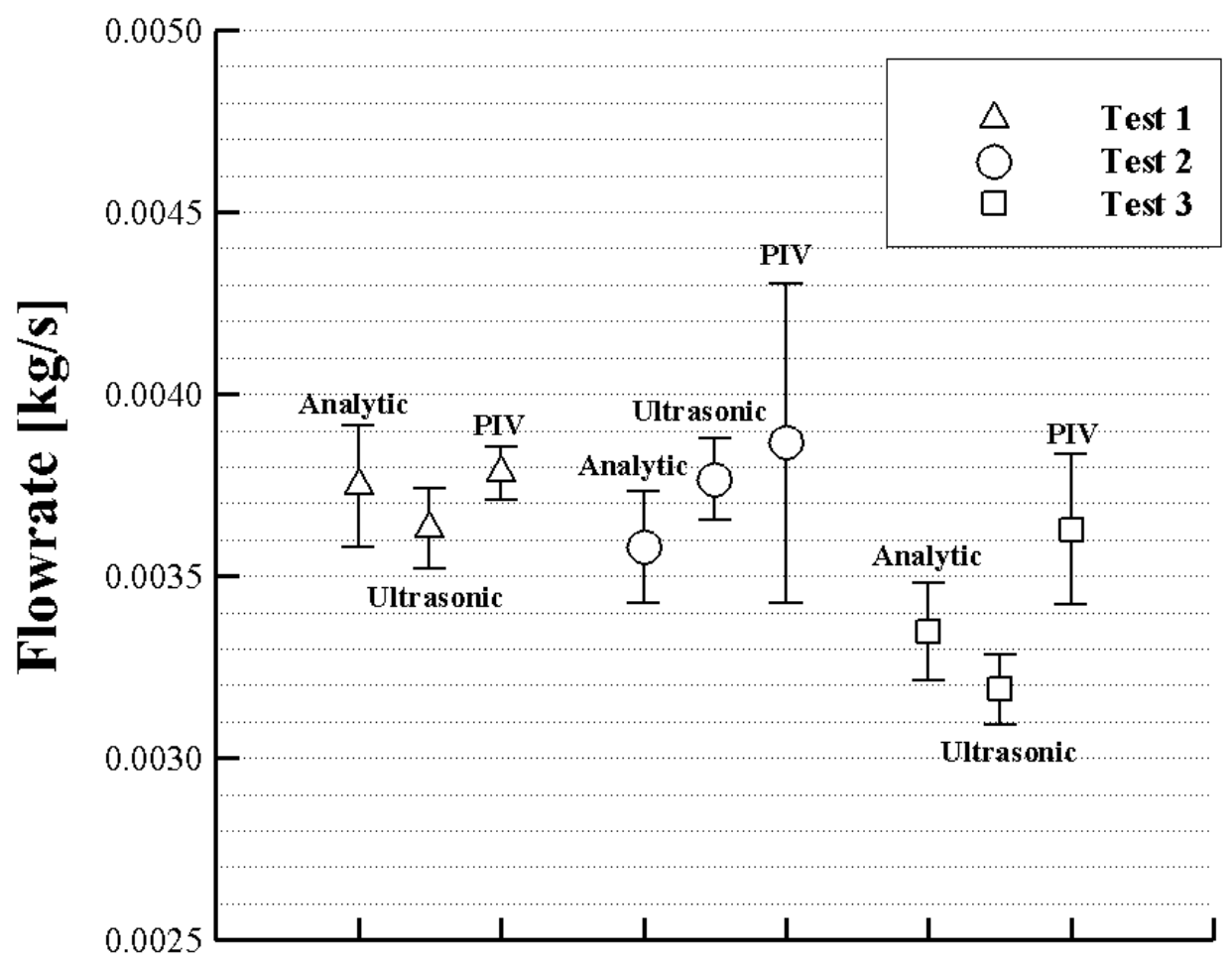

Fig. 25. Flow rate for a single pipe with different methods

Table 2. Flow rate uncertainties

\begin{tabular}{cccc}
\hline & Analytic & Ultrasonic & PIV \\
\hline Test 1 & $1.679 \mathrm{E}-04$ & $1.089 \mathrm{E}-04$ & $7.166 \mathrm{E}-05$ \\
Test 2 & $1.534 \mathrm{E}-04$ & $1.130 \mathrm{E}-04$ & $4.383 \mathrm{E}-04$ \\
Test 3 & $1.340 \mathrm{E}-04$ & $9.565 \mathrm{E}-05$ & $2.060 \mathrm{E}-04$ \\
\hline \hline
\end{tabular}

The Visualization Society of Japan (VSJ) proposed a guideline for performing an uncertainty analysis for a PIV system. The present uncertainty analysis was developed based on 
the VSJ recommendation [24]. Similar approach was performed in the works of DomiguezOntiveros and Hassan [25]. Four sources of uncertainty parameters were considered; the magnification factor $(\alpha)$, the displacement of particle image $(\Delta X)$, the time interval of successive images $(\Delta t)$, and the experiment uncertainty factor $(\delta \mathrm{u})$. The summary of PIV uncertainties are shown in Table 3, and the combined uncertainty was calculated using the Root-sum-square of the product of standard uncertainty and sensitivity coefficient. The largest uncertainty source in the present study is the mis-matching error between pair particle images and this can be significantly reduced by the improvement of PIV data processing.

Table 3. Summary of PIV system uncertainties from VSJ method

\begin{tabular}{|c|c|c|c|c|}
\hline Category & Error sources & $\begin{array}{c}\text { Standard } \\
\text { uncertainty }\end{array}$ & $\begin{array}{l}\text { Sensitivity } \\
\text { coefficient }\end{array}$ & $\begin{array}{l}\text { Combined } \\
\text { uncertainty }\end{array}$ \\
\hline \multirow{6}{*}{$\begin{array}{l}\text { Calibration } \\
\alpha(\mathrm{mm} / \mathrm{px})\end{array}$} & Reference image & 7.00E-01 px & $1.87 \mathrm{E}-04 \mathrm{~mm} / \mathrm{px}^{2}$ & \multirow{6}{*}{$6.92 \mathrm{E}-04 \mathrm{~mm} / \mathrm{px}$} \\
\hline & Physical distance & $2.00 \mathrm{E}-02 \mathrm{~mm}$ & $1.44 \mathrm{E}-031 / \mathrm{px}$ & \\
\hline & Image distortion by lens & $3.48 \mathrm{E}+00 \mathrm{px}$ & $1.87 \mathrm{E}-04 \mathrm{~mm} / \mathrm{px}^{2}$ & \\
\hline & Image distortion by CCD & $5.60 \mathrm{E}-03 \mathrm{px}$ & $1.44 \mathrm{E}-03 \mathrm{~mm} / \mathrm{px}^{2}$ & \\
\hline & Reference position & $5.00 \mathrm{E}-01 \mathrm{~mm}$ & $2.28 \mathrm{E}-041 / \mathrm{px}$ & \\
\hline & Parallel board & $3.50 \mathrm{E}-02 \mathrm{rad}$ & $4.55 \mathrm{E}-03 \mathrm{~mm} / \mathrm{px}$ & \\
\hline \multirow{3}{*}{$\begin{array}{c}\text { Acquisition } \\
\Delta X(\mathrm{px})\end{array}$} & Laser power fluctuation & $7.10 \mathrm{E}-03 \mathrm{~mm}$ & $7.69 \mathrm{E}+00 \mathrm{px} / \mathrm{mm}$ & \multirow{5}{*}{ 2.10E-01 px } \\
\hline & Image distortion by CCD & $5.60 \mathrm{E}-03 \mathrm{px}$ & $1.00 \mathrm{E}+00$ & \\
\hline & Normal view angle & $3.50 \mathrm{E}-02 \mathrm{rad}$ & $4.55 \mathrm{E}-03 \mathrm{~mm} / \mathrm{px}$ & \\
\hline \multirow{2}{*}{$\begin{array}{l}\text { Reduction } \\
\Delta X(\mathrm{px})\end{array}$} & Mis-matching error & $2.00 \mathrm{E}-01 \mathrm{px}$ & $1.00 \mathrm{E}+00$ & \\
\hline & Sub-pixel analysis & $3.00 \mathrm{E}-02 \mathrm{px}$ & $1.00 \mathrm{E}+00$ & \\
\hline \multirow{2}{*}{$\begin{array}{c}\text { Acquisition } \\
\Delta t(\mathrm{~s})\end{array}$} & Delay generator & $1.00 \mathrm{E}-08 \mathrm{~s}$ & $1.00 \mathrm{E}+00$ & \multirow{2}{*}{$1.41 \mathrm{E}-08 \mathrm{~s}$} \\
\hline & Pulse time & $1.00 \mathrm{E}-08 \mathrm{~s}$ & $1.00 \mathrm{E}+00$ & \\
\hline \multirow{2}{*}{$\begin{array}{l}\text { Experiment } \\
\delta \mathrm{u}(\mathrm{mm} / \mathrm{s})\end{array}$} & Particle trajectory & $5.00 \mathrm{E}-02 \mathrm{~mm} / \mathrm{s}$ & $1.00 \mathrm{E}+00$ & \multirow{2}{*}{$5.44 \mathrm{E}-02 \mathrm{~mm} / \mathrm{s}$} \\
\hline & 3-D effects & $2.15 \mathrm{E}-02 \mathrm{~mm} / \mathrm{s}$ & $1.00 \mathrm{E}+00$ & \\
\hline
\end{tabular}




\section{Summary}

A $1 / 16^{\text {th }}$ scaled VHTR experimental model was constructed and the preliminary test was performed in this study. To produce benchmark data for CFD validation in the future, the facility was first run at partial operation with five pipes being heated. PIV was performed to extract the vector velocity field for three adjacent naturally convective jets at statistically steady state. A small recirculation zone was found between the pipes, and the jets entered the merging zone at 3 $\mathrm{cm}$ from the pipe outlet but diverged as the flow approached the top of the test geometry. Turbulence analysis shows the turbulence intensity peaked at $41-45 \%$ as the jets mixed. A sensitivity analysis confirmed that 1,000 frames were sufficient to measure statistically steady state. The results were then validated by extracting the flow rate from the PIV jet velocity profile, and comparing it with an analytic flow rate and ultrasonic flowmeter; all flow rates lie within the uncertainty of the other two methods for Tests 1 and 2. This test facility can be used for further analysis of naturally convective mixing, and eventually produce benchmark data for CFD validation for the VHTR during a PCC or DCC accident scenario.

\section{Acknowledgment}

The study is supported by the Nuclear Energy University Program (NEUP) of U.S. Department of Energy (DOE). 


\section{References}

1. Doug Chapin, S.K., Jim Nestell, The Very High Temperature Reactor: A Technical Summary. 2004: MPR Associates Inc.

2. Gauthier, J.-C., et al., ANTARES: The HTR/VHTR Project at Framatome ANP. Nuclear Engineering and Design, 2006. 236(5-6): p. 526-533.

3. Chang, J., et al., A Study of a Nuclear Hydrogen Production Demonstration Plant. Nuclear Engineering and Technology, 2007. 39(2): p. 111.

4. Condie, K., et al., Development of an Experiment for Measuring Flow Phenomena Occurring in a Lower Plenum for VHTR CFD Assessment. 2005: Idaho National Laboratory.

5. Elder, R. and R. Allen, Nuclear Heat for Hydrogen Production: Coupling a Very High/High Temperature Reactor to a Hydrogen Production Plant. Progress in Nuclear Energy, 2009. 51(3): p. 500-525.

6. Khamis, I. Nuclear Power Plants Can Produce Hydrogen to Fuel the "Hydrogen Economy”. in ACS Press Conference. 2012. San Diego, California: American Chemical Society

7. Haque, H., W. Feltes, and G. Brinkmann, Thermal Response of a Modular High Temperature Reactor during Passive Cooldown under Pressurized and Depressurized Conditions. Nuclear Engineering and Design, 2006. 236(5-6): p. 475-484.

8. Chang, H.O., C. Davis, and R. Moore, Development of Safety Analysis Codes and Experimental Validation for a Very High Temperature Gas-Cooled Reactor. 2004, Idaho National Laboratory (INL).

9. Reyes Jr, J., et al., Scaling Analysis for the High Temperature Gas Reactor Test Section (GRTS). Nuclear Engineering and Design, 2010. 240(2): p. 397-404.

10. Gougar, H. and C. Davis, Reactor Pressure Vessel Temperature Analysis for Prismatic and Pebble-Bed VHTR Designs. Idaho National Laboratory, 2006.

11. McIlroy, H., et al., PIV Experiments to Measure Flow Phenomena in a Scaled Model of a VHTR Lower Plenum. Idaho National Laboratory Report INL/INT-06-11740, 2006.

12. Johnson, R.W., D.P. Guillen, and T. Gallaway, Investigations of the Application of CFD to Flow Expected in the Lower Plenum of the Prismatic VHTR. 2006: Idaho National Laboratory.

13. Tung, Y.-H. and R.W. Johnson. CFD Calculations of Natural Circulation in a High Temperature Gas Reactor Following Pressurized Circulator Shutdown. in ASME 2011 International Mechanical Engineering Congress and Exposition. 2011. American Society of Mechanical Engineers.

14. McCreery, G.E. and K.G. Condie, Experimental Modeling of VHTR Plenum Flows during Normal Operation and Pressurized Conduction Cooldown. 2006, INL/EXT-0611760, Idaho National Laboratory, Idaho Falls, Idaho 83415.

15. Westerweel, J., G.E. Elsinga, and R.J. Adrian, Particle Image Velocimetry for Complex and Turbulent Flows. Annual Review of Fluid Mechanics, 2013. 45(1): p. 409-436.

16. Thielicke, W. and E.J. Stamhuis, PIVlab-Towards User-friendly, Affordable and Accurate Digital Particle Image Velocimetry in MATLAB. Journal of Open Research Software, 2014. 2(1): p. e30. 
17. Sanchez, T., et al., Spontaneous Motion in Hierarchically Assembled Active Matter. Nature, 2012. 491(7424): p. 431-434.

18. Booth-Gauthier, E.A., et al., Force-Induced Changes in Subnuclear Movement and Rheology. Biophysical journal, 2012. 103(12): p. 2423-2431.

19. Leong, T., et al., The Role of Surfactant Headgroup, Chain Length, and Cavitation Microstreaming on the Growth of Bubbles by Rectified Diffusion. The Journal of Physical Chemistry C, 2011. 115(49): p. 24310-24316.

20. Mirsepassi, A. and D. Rankin, Particle Image Velocimetry in Viscoelastic Fluids and Particle Interaction Effects. Experiments in Fluids, 2013. 55(1): p. 1-7.

21. Piro, V., N. Piro, and O. Piro, Characterization of Intraventricular Blood Flow using a Microbubble-Contrast Tracking Echo-PIV Technique. Journal of the American College of Cardiology, 2012. 59(13s1): p. E1139-E1139.

22. $\mathrm{Xu}, \mathrm{H}$. and E. Bodenschatz, Motion of Inertial Particles with Size Larger than Kolmogorov Scale in Turbulent Flows. Physica D: Nonlinear Phenomena, 2008. 237(14): p. 2095-2100.

23. Amini, N. and Y.A. Hassan, Measurements of Jet Flows Impinging into a Channel Containing a Rod Bundle using Dynamic PIV. International Journal of Heat and Mass Transfer, 2009. 52(23-24): p. 5479-5495.

24. ITTC, S.C.o.U.A.o.t. Uncertainty Analysis Particle Imaging Velocimetry. in International Towing Tank Conference. 2008.

25. Dominguez-Ontiveros, E. and Y.A. Hassan, Experimental Study of a Simplified $3 \times 3$ Rod Bundle using DPTV. Nuclear Engineering and Design, 2014. 279(0): p. 50-59. 